Article

\title{
Emergence of Animals from Heat Engines - Part 1. Before the Snowball Earths
}

\author{
Anthonie W.J. Muller \\ Swammerdam Institute for Life Sciences, University of Amsterdam, 1090GE Amsterdam, \\ The Netherlands; E-Mail: a.w.j.muller@uva.nl
}

Received: 20 August 2009 / Accepted: 15 September 2009 / Published: 18 September 2009

\begin{abstract}
The origin of life has previously been modeled by biological heat engines driven by thermal cycling, caused by suspension in convecting water. Here more complex heat engines are invoked to explain the origin of animals in the thermal gradient above a submarine hydrothermal vent. Thermal cycling by a filamentous protein 'thermotether' was the result of a temperature-gradient induced relaxation oscillation not impeded by the low Reynolds number of a small scale. During evolution a 'flagellar proton pump' emerged that resembled Feynman's ratchet and that turned into today's bacterial flagellar motor. An emerged 'flagellar computer' functioning as Turing machine implemented chemotaxis.
\end{abstract}

Keywords: evolution; flagellar motor; Feynman's ratchet; non-equilibrium thermodynamics; Reynolds Number; Snowball Earth; thermosynthesis; Turing machine

PACS Codes: 87.23.Kg, 87.19.Pp, 87.15.Zg

\section{Introduction}

Thermosynthesis involves the idea of biological heat engines that work on thermal cycling (Figure 1). In previous studies the notion was applied in models for the origin of life and the origin of photosynthesis [1-8], i.e., the origin of plants. In these studies the required thermal cycling was the effect of suspension in convecting water such as present in volcanic hot springs. 
Figure 1. The previously proposed thermosynthesis mechanism based on a thermal variation of the binding change mechanism. (a) During chemiosmosis - a partial process of both respiration and photosynthesis - the key biological energy carrier ATP is generated inside the $\mathrm{F}_{1}$ moiety of the ATP Synthase enzyme. Bound ADP and phosphate form tightly bound ATP. When protons cross the membrane from high to low electric potential in the $F_{o}$ moiety of ATP Synthase, their free energy is transduced (crooked arrow) to the $F_{1}$ moiety of ATP Synthase, causing the bound ATP to be released. (b) It is proposed that in the first protein (FP) the release of similarly formed bound ATP was effected by thermal unfolding.

\section{a. Today's $F_{1}$ moiety of ATP Synthase}

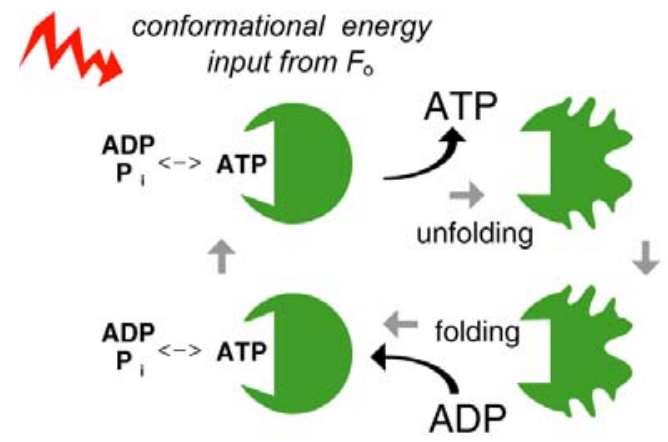

b. Proposed First Protein (FP)

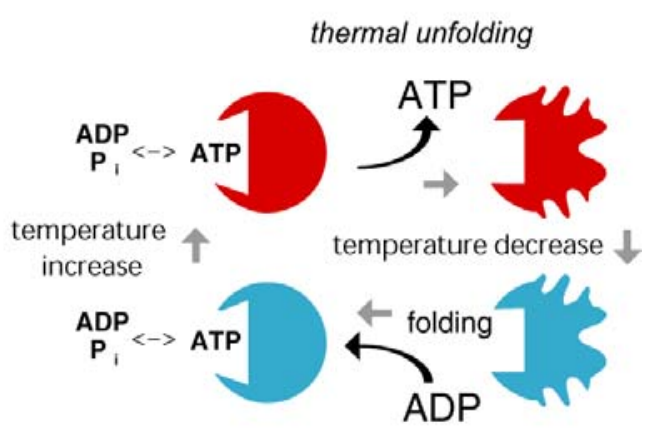

Large multicellular animals (metazoans) suddenly emerge in the fossil record of the late Proterozoic [9-16], right after a series of extensive glaciations, 'Snowball Earths' [17-19] that date from 750-550 Ma (Million years ago). Here we present the first in a series of studies that explains the origin of animals by thermosynthesis; a preliminary version of the follow-up paper describing the emergence of the Ediacaran animals is available [20]. The thermosynthesizing ancestors of the animals would have lived, not on convection, but on the thermal gradient between cold ocean water and hot submarine hydrothermal vents [20,21]. These ancestors may have done so rather early, in the Archaean, 3,235 Ma, since fossils from that time already suggest the occurrence of protein conformational changes driven by a thermal gradient [22]. It is hypothesized that shape oscillations sustained ATP synthesis at a time of a global glaciation. The first cell organelle with this capability was a protein 'thermotether' that in the thermal gradient performed a relaxation oscillation [23] caused by reversible low-temperature $\left(\sim 0{ }^{\circ} \mathrm{C}\right)$ unfolding, also called 'cold denaturation' (Figure 2) [24,25]. Merger of parts of ATP Synthase with the type-III protein export complex [26] then yielded a flagellar proton pump (Figure 3) that resembled.

A Feynman ratchet [27-29]. The bacterial flagellar motor [30] evolved from the flagellar pump when it reversed at the end of a global glaciation, after protons pumped by respiration had again become available. We end by considering the emergence of computers similar to Turing machines [31] from flagellar motors.

Thermosynthesis draws heavily on chemiosmosis, the ubiquitous mechanism of ATP synthesis [32-36]. Although widely used in explaining physiological phenomena, application of chemiosmosis to the modelling of evolution and the origin of life is still rare [37]. 
Figure 2. A thermotether that works on a relaxation oscillation in a thermal gradient is combined with the First Protein, yielding an ATP generator that works on a thermal gradient. In the thermal gradient above a hydrothermal vent, the thermotether performs a relaxation oscillation: while warm it folds, but as the relaxed folded and relaxed unfolded proteins have different shapes, the new conformation is under strain. It cannot instantaneously relax to the new equilibrium shape. After relaxation by expansion, the thermotether comes in contact with the cold ocean water and cools. Cold denaturation sets in, which changes the conformation. The protein is again first in strain, and then relaxes, this time by contraction, to a shape in which it is in thermal contact with the hydrothermal vent. An attached FP that works on cold denaturation (instead of on the hot denaturation process shown in Figure 1) enables the synthesis of ATP from the thermal cycling caused by the thermotether oscillating in the thermal gradient.

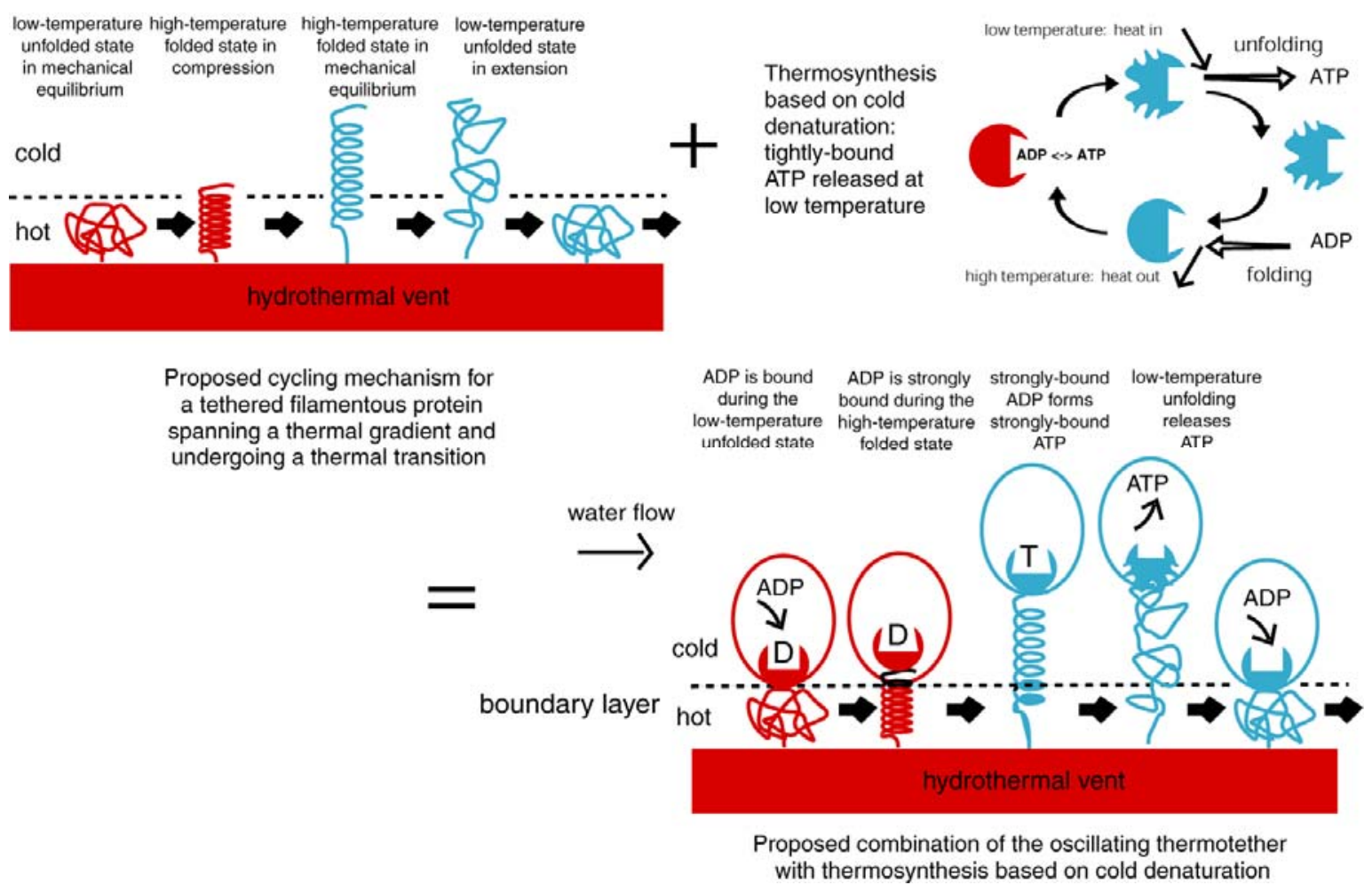

Figure 3. Overview of the proposed evolution of flagellum-based heat engines that worked on a thermal gradient. As the processes occur in a dissipative thermal gradient, they concern applications of non-equilibrium thermodynamics. (a) In a bacterium carried along by convection above a hydrothermal vent a proton pump $P$ was driven by thermal cycling [4]. The resulting proton gradient drove ATP Synthase and the uptake of nutrients by $\mathrm{H}^{+} /$nutrient symport (sym). Since the mechanism does not require sunlight, it could have worked during a global glaciation. (b) A filamentous protein $T$ was attached to a hydrothermal vent, which permitted thermal cycling caused by temperature fluctuations on the surface of a hydrothermal vent. By turning into a thermotether, the filamentous protein permitted free energy gain from a constant vent temperature as well. (c) The proton pump combined with the thermotether to form a flagellar pump (FPump). (d) After the end of a global glaciation, addition of the respiratory chain to the bacterial membrane enabled 
proton pumping by respiration while electrons moved from reductant to oxidant. Following disconnection of the flagellum from the hydrothermal vent, the flagellar pump functioned as flagellar motor $(F M)$ while the proton flow through the flagellar pump reversed. (e) Proton pumping by the flagellar ratchet $(F R)$ could be sustained by (1) a thermal difference between the flagellum and the stator in the flagellar motor, but also by mechanical movement of the flagellum due to (2) non-thermal fluctuations or even (3) a steady flow. (f) Emergence of today's bacterial flagellar computer $(F C)$ in a bundle of flagella. One flagellum temporarily interrupts the cooperative functioning of the bundle, causing 'tumbling', a random change in direction. The frequency of tumbling is determined by chemoreception; chemoreceptors modify Che-Y proteins, which in turn affect the resetting delay of the FC. Such a flagellar motor resembles the Turing machine. (g) Instead of using protons, the eukaryotic flagellum works on ATP. It emerged upon symbiosis of (1) an ATP-yielding bacterium with (2) a host that descended from a flagellated bacterium in which the flagellar bundle had acquired an enclosing membrane and the flagella had been replaced by microtubules. The data processing capability of the eukaryotic cell (the 'eukaryotic computer') descended from the bacterial flagellar computer.

\section{a. Carried along by convection}
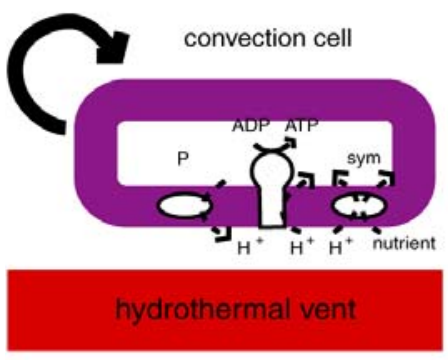

d. Flagellar motor

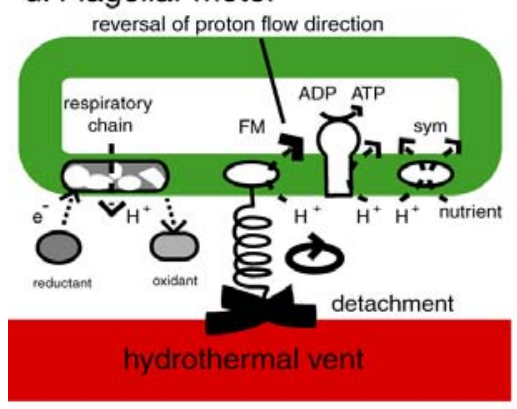

f. Flagellar computer

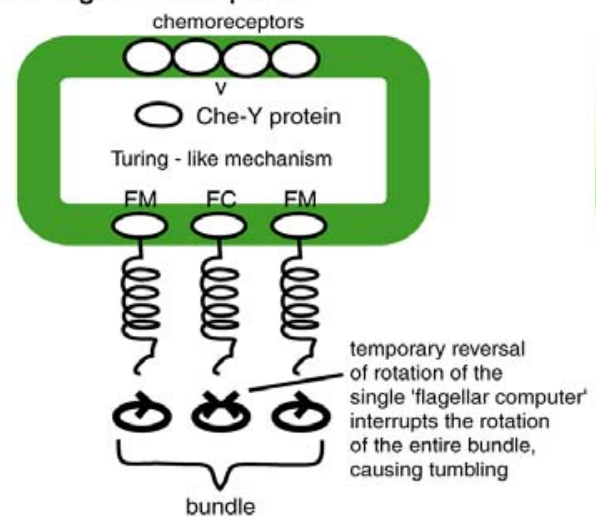

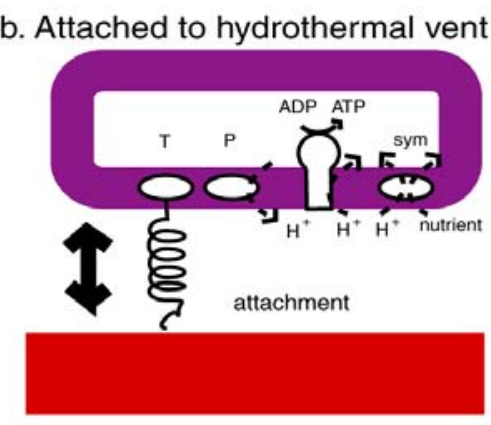

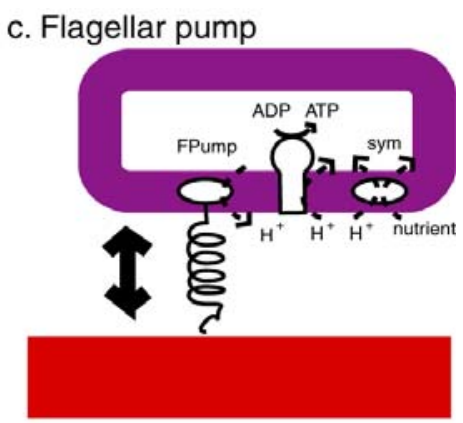

e. Flagellar ratchet

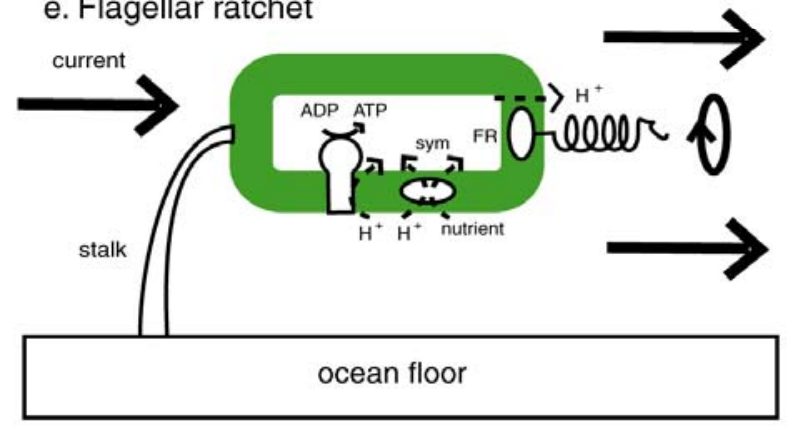

g. Proposed eukaryotic computer
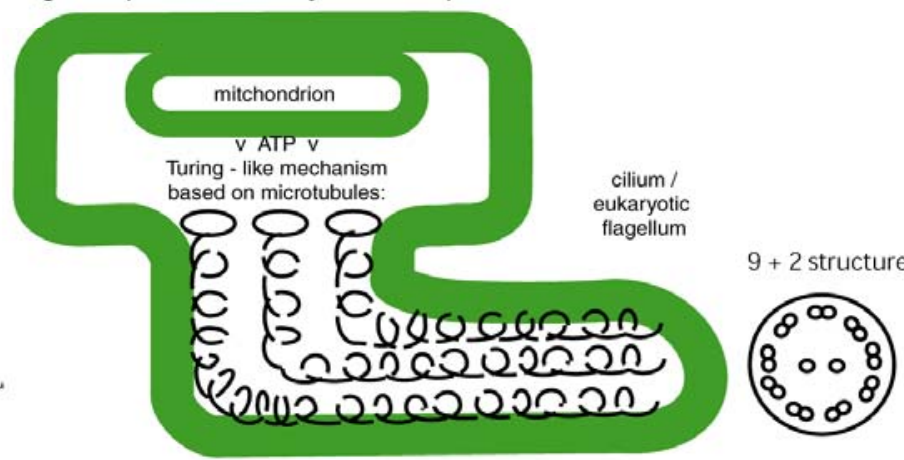
Here we give a general introduction to a series of papers on the emergence of animals. We moreover consider thermosynthesis at hydrothermal vents early in the Proterozoic. The following studies will consider (1) the emergence of the Ediacaran organisms at hydrothermal vents during the late Proterozoic, (2) the Cambrian explosion, and (3) physiological effects of the temperature in today's animals.

\section{Background}

\subsection{Simple Heat Engines}

In physics and engineering the notion of a heat engine is well established. Many types have been described. The working substance can be a solid, liquid, vapour or a gas [38]. In addition to the familiar steam engine and the somewhat less familiar Stirling gas engine, heat engines have been constructed or proposed based on many principles, including temperature-dependent electric [39-42] and magnetic polarization [43], and shape memory of a metal [44]. Rubber is derived from a biological material produced by plants. It contracts with the temperature [45] and heat engines based on rubber [46-48] are of interest since proteins such as collagen, fibroin and elastin contract in the same way [4951]. More generally, almost any temperature-dependent material characteristic seems applicable in a heat engine.

Heat engines such as the gas turbines that sustain jet propulsion and drive electric power generators are complex in their construction of advanced materials [52] because of the benefit of closely approaching, at maximal temperature difference, the optimal Carnot efficiency. Complexity is, however, not inherent to heat engines. The convection cell, in which the rotating fluid does mechanical work, demonstrates that a heat engine can even be self-organizing. Convection is a ubiquitous and important process. Ultimately, most of the order in the Universe is derived from convection. Carnot [38] already observed:

To heat ... are due the vast movements which take place on the Earth,

and convection indeed sustains the weather in the atmosphere, the ocean currents in the hydrosphere, the plate tectonics in the lithosphere, and may sustain the geodynamo in the Earth's core that generates the Earth's magnetic field [53-55].

The previously proposed thermosynthesis processes invoked to explain the origin of life made use of convection in volcanic hot springs. The thermosynthesis processes considered in this study and the following ones are based on relaxation oscillations in the thermal gradient between a submarine hydrothermal vent and the ocean. This gradient derives from two grand convection cells. The heat source, the vent, is the result of the large convection cells in the Earth's mantle that drive plate tectonics [56], and the heat sink, the cold ocean water, results from the thermohaline circulation in the ocean [57]. In a large convection cell, warm ocean currents move along an erratic wind-driven path [58] along the ocean's surface from the tropics to convergence zones near the poles where the water cools, becomes more dense, sinks, and returns along the ocean floor-passing by the hydrothermal vents - to the tropics where upwelling occurs.

Simple but inefficient heat engines are of little interest to engineering but may still be of use in biology. A low efficiency is not a drawback when the heat source is freely available low grade heat. 
Since the middle of the nineteenth century there have been several proposals for the application of heat engine mechanisms to the life sciences [59-62], especially for muscle [63]. For this organ the application fails $[64,65]$. The absence of detectable thermal gradients in muscle is incompatible with a heat engine mechanism given the muscle's known high efficiency. This incompatibility does not, however, contradict the emergence of muscle or of other organs from a heat engine.

In physics a heat engine is defined as a system that performs mechanical work with simultaneous heat transport from high to low temperature. In this study a system is also called a heat engine when heat transport down a thermal gradient is accompanied by the generation of a high free energy substance such as ATP.

Work is readily interchanged with kinetic energy. A relaxation oscillation can be driven by a change in temperature that causes a shape change that disconnects the thermal contact-which caused the temperature change in the first place (Figure 4). Bimetal is a combination of (1) invar, an alloy (FeNi36) that does not expand with the temperature [66], and (2) an alloy that does. Car signalling lights are an application of a similar relaxation oscillation. Light emission stops when an electrical current is interrupted by an electrical contact broken by a bending of the bimetal, the result of the temperature increase caused by the current: the current switches itself off after it was switched on.

Figure 4. Relaxation oscillations in a thermal gradient based on shape changes with the temperature. In the upper cartoon the working solid is permanently connected at one end to a hot reservoir while the other end is free and intermittently connects to the cold reservoir; in the lower cartoon the working solid is permanently connected to the cold reservoir and the free end intermittently connects to the hot reservoir. In both systems an expansion due to a temperature change results at the free end in a thermal contact that opposes the temperature change, yielding an oscillation in shape and temperature.

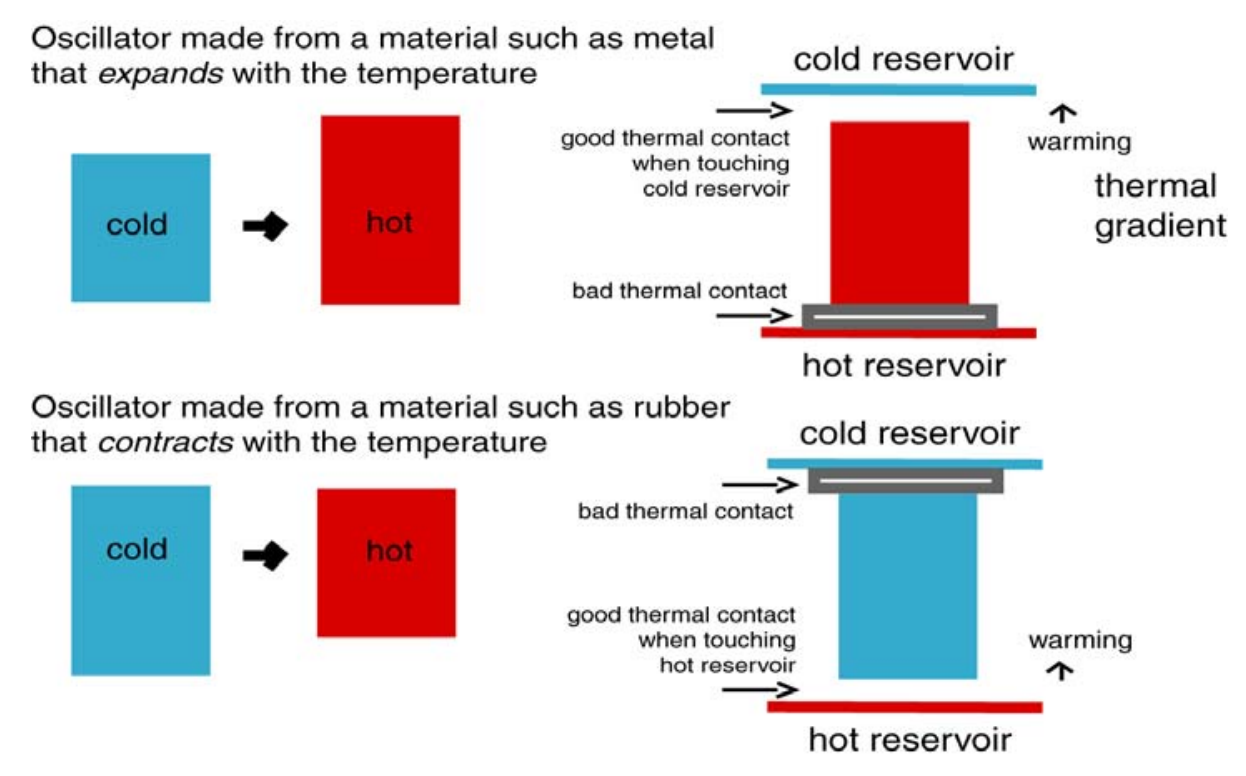




\subsection{The Chemiosmotic Mechanism}

Are biological heat engines possible? If a biological heat engine could be imagined, the well known adaptability of life, as shown by its versatility in using many chemical energy sources [67], would make it plausible that at least a few organisms could make use of this physical energy source as well.

Figure 5. Basic principles of chemiosmosis. During both photosynthesis and respiration protons are pumped across a biomembrane, which stores the free energy generated. The ATP Synthase enzyme transduces the free energy of this Proton Motive Force (PMF) into the free energy of ATP (Figure 1).

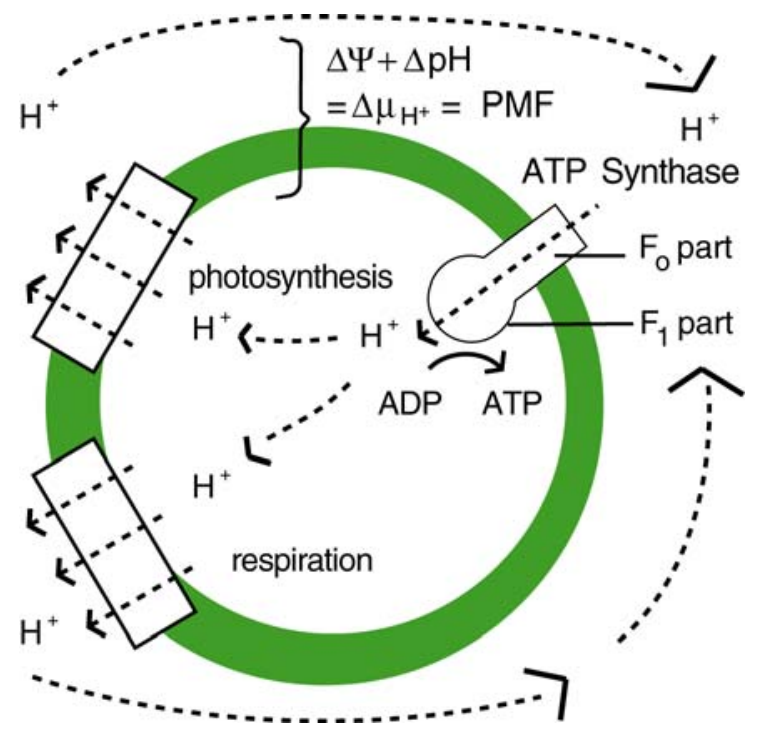

In life, the ATP molecule is the energy currency. Almost all ATP is generated by the chemiosmotic mechanism, the biological energy conversion process that sustains both respiration and photosynthesis [34-36]. Its machinery consists of enzymes and a biomembrane. The electrical potential difference across this biomembrane is part of the energy transduction process (Figure 5). During respiration, electrons move from a reductant to an oxidant while simultaneously protons are pumped across a membrane; during photosynthesis, electrons excited by light also drive proton pumping. The free energy of protons at the high electrical membrane potential is transduced by the ATP Synthase enzyme into ATP while the pumped protons fall back through the membrane to the lower potential.

The $\Delta G_{0}$ ATP of ATP synthesis is $30 \mathrm{~kJ} / \mathrm{mol}$ [68], and depends strongly on the $\mathrm{pH}$ and concentration of $\mathrm{Mg}^{2+}$. The ADP and ATP concentrations are also highly variable; the in vivo $\Delta G_{\text {ATP }}$ therefore can also vary strongly, and can be as high as $50 \mathrm{~kJ} / \mathrm{mol}$ [69]. These values correspond to electrical membrane potential differences of

$$
\Delta \Psi_{1}=\Delta G_{\mathrm{ATP}} / F=310, \text { resp. } 520 \mathrm{mV}
$$

where $F$ is Faraday's constant. A value that we will use for numerical estimates is $360 \mathrm{mV}$ [70]. A difference in $\mathrm{pH}$ across the membrane, $\Delta \mathrm{pH}$, can drive ATP synthesis too (a process driven by a difference in $\mathrm{pH}$ is endothermic [71], just as the entropy rising step in the T-S cycle of a heat engine). A combination of $\Delta \mathrm{pH}$ and $\Delta \Psi$ also works, and is called the electrochemical proton gradient across 
the membrane', symbol $\Delta \mu$; another name for the combination is 'proton motive force', abbreviated as PMF.

During the transduction by chemiosmosis of $\Delta \Psi$ into ATP, protons cross the membrane. The $\mathrm{H}^{+}$/ATP ratio number $n$ has been named the 'coupling ratio' [72]; an extensive literature deals with the coupling ratio, for recent studies see Toei et al. [73], Tomasek and Brusilow [74] and Steigmiller et al. [75]. The minimal membrane potential $\Delta \Psi_{\mathrm{n}}$ for ATP synthesis at a ratio $n$ equals:

$$
\Delta \Psi_{\mathrm{n}}=\Delta \Psi_{1} / n
$$

At a potential lower than $\Delta \Psi_{\mathrm{n}}$ the enzyme can only function as a pump that sends protons across the membrane at the cost of ATP (Figure 6). Assuming the just mentioned value of $360 \mathrm{mV}, \Delta \Psi_{3}$ becomes $120 \mathrm{mV}$ for $n=3$, and $\Delta \Psi_{5}$ becomes $72 \mathrm{mV}$ for $n=5$.

Figure 6. $I-V$ curve of a simple ATP Synthase. The magnitude and direction of the proton current ('I') through ATP Synthase depends on the PMF ('V') and the proton:ATP ratio under which the enzyme operates. At low PMF the enzyme works as a proton pump and consumes ATP, at high PMF it generates ATP.

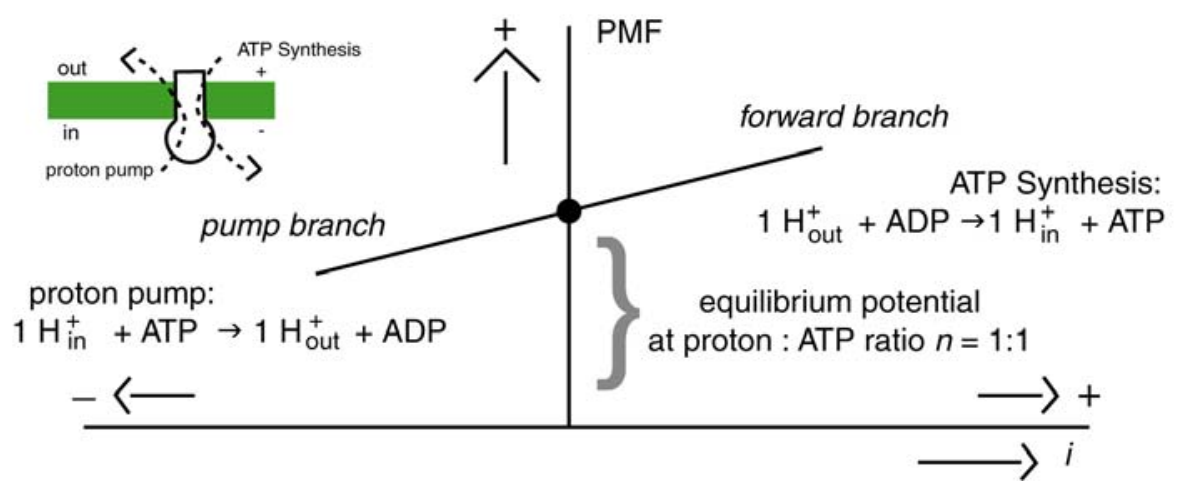

Figure 7. Net dissipation of ATP ('futile cycle') when two ATPases with different stochiometries are operating simultaneously, one as ATP Synthase (forwards), the other as ATPase (backwards). At the mixing potential $\mathrm{E}_{\mathrm{m}}$ the ATP yielded by the forward current equals half the ATP consumed by the pump current.

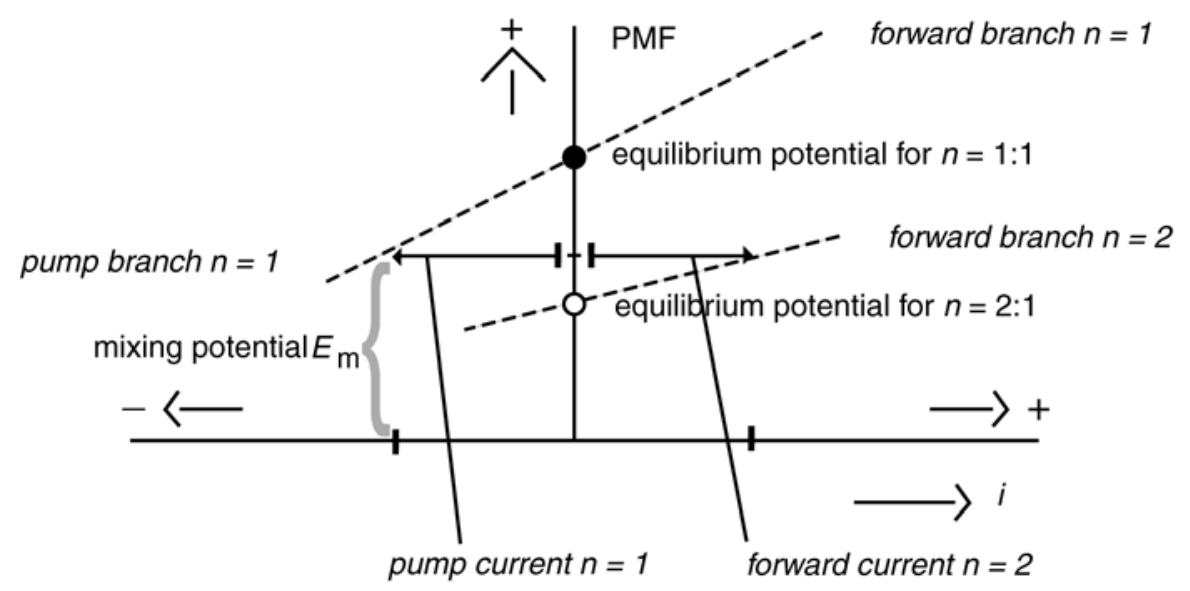


Different proton translocating enzymes have a different value for $n$ : the cell uses ATPases with a low $n$ value to acidify cell organelles, for instance for digestion of food. When a membrane contains two ATP Synthases active with different ratios (in Figure 7, $n=1$ and 2), the result is a net dissipation of ATP (discussed for $\mathrm{Ca}^{2+}$ ATPases with different $n$ values [76]). The membrane potential then assumes a value between the equilibrium potentials of the two $n$ values. This dissipative process has been called a 'futile cycle' [77]. In the V-ATPase of the plant vacuole membrane the coupling ratio can vary from 4 to 2 as the $\Delta \Psi$ increases [74]. The variation has been attributed to a variable intensity of dissipative proton transport through the ATP Synthase ('slip' or 'intrinsic uncoupling') that would not affect ATP synthesis / hydrolysis [78]. The $\mathrm{F}_{0} \mathrm{~F}_{1}$-ATP Synthase in mitochondria and chloroplasts functions at higher ratios, 3 to 5; much higher values $\sim 20$ have however also been reported [79-81].

The ATP Synthase enzyme contains two moieties, the membrane bound $F_{o}$ part and the waterimmersed $F_{1}$ part [82]. The $F_{o}$ part contains the translocator of the protons across the membrane. The $\mathrm{F}_{1}$ part is itself composite, containing three $\alpha$ and three $\beta$ subunits that alternate in a ring. The $\alpha$ and $\beta$ subunits are similar, the difference being that whereas the nucleotides on the $\alpha$ subunit cannot be exchanged with the medium, the nucleotides on the $\beta$ subunit can: here the ATP is synthesized (or, conversely, hydrolysed during the reverse process). The ATP synthesis occurs by Boyer's [83] 'binding change mechanism'. The bound ADP and phosphate spontaneously form ATP in the local dry conditions [84]. This ATP remains strongly bound. In the energy transducing step, the bound ATP is released when protons move through $\mathrm{F}_{\mathrm{o}}$ from one side of the membrane to the other (Figure 1a).

\subsection{Thermosynthesis Based on Convection (TSC)}

Many heat engines involve thermal transitions, and ATP-generating biological heat engines could plausibly involve thermal transitions in the proteins and membranes that sustain chemiosmosis. More specifically, the thermal transition would concern the thermal unfolding of the protein ATP Synthase [4] or the thermotropic phase transition of the lipid membrane [3]. Thermal cycling would be due to the circulation of the fluid in a convection cell. The previously proposed two heat engines work on this thermal cycling, 'Thermosynthesis by Convection' (TSC). The mechanisms have been applied in models for the origin of life [4-5] and the emergence of photosynthesis $[5,6,85,86]$.

During the origin of life, the proposed mechanism of the first protein (FP) is a thermal variation of the binding change mechanism of ATP Synthase [84] that has been called 'protein-associated thermosynthesis' (PTS) (Figure 1). Thermal cycling would have caused the FP to synthesize by 'enzymatic promiscuity' [87-91] several high-energy condensation products: in addition to ATP and other nucleoside triphosphates, phospholipids, randomly constituted peptides and RNA ${ }^{1}[4,5]$. The FP would reverse reactions similar to the hydrolysis of amide and P-O bonds supported by the promiscuous enzyme aminopeptidase $\mathrm{P}$ [92]. The contemporary enzyme most closely related to the FP would be the $\beta$ subunit of ATP Synthase. ${ }^{2}$ Today, ATP Synthases still show high $[93,94]$ and low temperature unfolding [95].

A key distinction between the FP and almost all regular enzymes (ATP Synthase is an exception [96]) is that whereas regular enzymes catalyse both the forward and backwards reaction, and diminish the free energy, the proposed ancient FP during thermal cycling generated a stable high energy product. Just as in ATP Synthase today [96], some partial steps of the FP must have been 
irreversible in order to avoid the decay of the high energy product by the reverse reaction [4], a regulation that would have been controlled by the temperature. This kinetic irreversibility should be distinguished from the assumed conformational reversibility during thermal cycling of the FP. During some partial processes of the thermal cycle the conformational changes would have been irreversible, but at the end of the thermal cycle the original conformation would have been regained (this conformational reversibility contrasts with the irreversibility of thermal denaturation of many proteins).

In the second heat engine mechanism, a change in coupling ratio was synchronized with variation in the dipole potential of the biomembrane during a thermotropic phase transition in the membrane [3]. This 'membrane-associated thermosynthesis' (MTS) is a proposed progenitor of bacterial photosynthesis, with as an intermediate link a mechanism based on a light-induced dipole potential effected by light-dark cycling $[6,85,86]$. An early ATP Synthase would have been able to vary the coupling ratio, for instance with the temperature. By (1) pumping protons across the membrane at a high coupling ratio and low potential (say 5 protons at a cost of 1 ATP molecule), (2) letting a physical process (temperature change, light absorption) increase the membrane potential by evoking a dipole layer with a high enough dipole potential, and (3) letting protons fall down at low coupling ratio and high potential (say 1 ATP per proton), net ATP could be won (in this example, $5-1=4$ ATPs) (Figure 8). A variability of the coupling ratio in present day ATP Synthase is consistent with the frequent experimental difficulty of establishing an integer value for it [75].

Figure 8. A fluctuating membrane PMF (or voltage) permits ATP gain, either from two different ATP Synthases with a different proton-ATP ratio, or from a single ATP Synthase with a variable proton ATP ratio. At high PMF and low proton:ATP ratio, more ATP is synthesized from the forward current than is later consumed by the pump current at low PMF and high proton:ATP ratio when the same charge is pumped again across the membrane. The activity of the concerned enzymes must be properly regulated (switched on and off) by the PMF in order to avoid the dissipation shown in Figure 7.

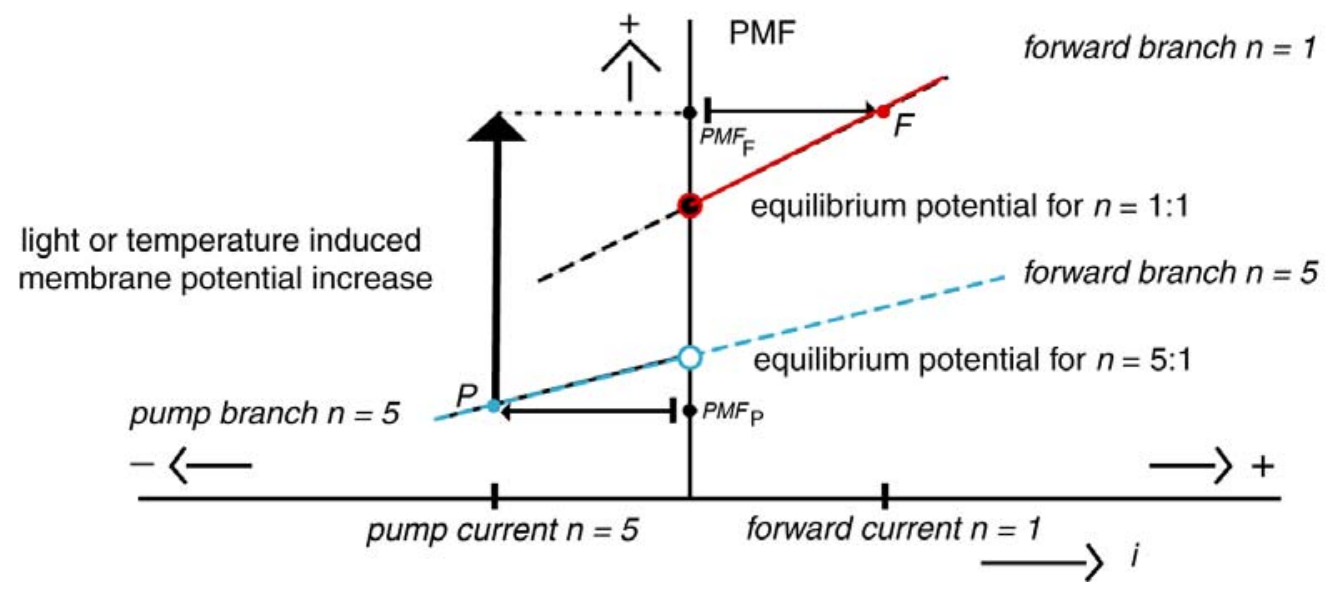

An organism carried along by a convective current is passively moved, and photosynthesis may have emerged when the effects of a light gradient in the convection cell added on to the effects of the thermal gradient [6]. Compared to photosynthesis and respiration, thermosynthesis such as by PTS has 
a low power, since a single FP yields only one ATP molecule per thermal cycle. The cycle time of a rotation convection cell is expected to be in the range of seconds or longer. The turnover time of FP would be much larger than the turnover time of today's ATP Synthase during photosynthesis or respiration, which can be as low as $\sim 10 \mathrm{~ms}$ [32]. The power (energy produced per unit time) of these last two processes is therefore much higher than the power of thermosynthesis, clearly a selective advantage. On the other hand, the light and food they require are not always and have not always been available at all places and at all times, in particular not during the winter near the Poles at high latitudes and, at all latitudes, during the global glaciations of the Archaean and the Proterozoic.

\subsection{The Fire: Hydrothermal Vents}

After their discovery in 1977 [99], a role of hydrothermal vents in the origin and evolution of life was proposed [100,101]. The temperature in black smoker gases leaving the hydrothermal vents can be as high as $350{ }^{\circ} \mathrm{C}$ [99]; recently [102] a temperature above the critical temperature of seawater, at 298 bar, $407^{\circ} \mathrm{C}[103,104]$, was reported. The at first sight appealing idea that large biomolecules could be formed within the black smokers is however incorrect, since these molecules decompose long before they reach a temperature of $350{ }^{\circ} \mathrm{C}$; even amino acids are unstable at these high temperatures [105].

Due to the thermohaline circulation [57], the water at the bottom of the ocean is just a few degrees above freezing, which results in a large thermal gradient in the boundary layer of the water flowing over the hydrothermal vent. This large thermal gradient decreases with distance to the vent; smaller thermal gradient must be present as well. Moreover, some hydrothermal vents and mounds show maximal temperatures much lower than $350{ }^{\circ} \mathrm{C}[106,107]$. Although temperatures around $100{ }^{\circ} \mathrm{C}$ may still be too high to start life [108]:

RNA and DNA are clearly too unstable to exist in a hot prebiotic environment.

Today's organisms can live at such a temperature, and it follows from rRNA sequences that the last common ancestor of all living organisms lived at such a high temperature of $\sim 100{ }^{\circ} \mathrm{C}[109]$.

Sites of lower temperature $\left(\sim 80^{\circ} \mathrm{C}\right)$ at hydrothermal vents / mounds have been proposed as sites for prebiotic reactions that generate the substances required for the origin of life [110-113]. However, this temperature of $\sim 80^{\circ} \mathrm{C}$ is still high enough to destabilize nucleic acids. Only a temperature below freezing point is conducive to the formation of stable bases of nucleic acids [114].

Whereas some researchers favour a hot origin of life [100,115,116], other origin-of-life researchers favour a cold one [117,118]. Thermosynthesis suits as bridge for the gap between the seemingly antithetic hot and cold origins since it involves convection, which requires a thermal gradient, i.e., both a high and a low temperature. More generally, the thermosynthesis theory invokes dynamic temperatures as key agent: the origin of life would have required 'thermal turmoil'. The heat produced by episodic meteorite impacts must have made the surface temperature of the early Earth far from static.

\subsection{The Ice: Glaciations on the Early Earth}

In order to understand early global glaciations we consider what determined Earth's surface temperature in the past. Initially it must have been very high due to the heat released during the 
gravitational collapse that formed the Earth 4,5 Ga. Thereafter, gravitation remained a large heat source during intermittent meteorite impacts; the impact that resulted in the formation of the Moon must have remelted the Earth's surface [119]. The formed Moon was itself hit by meteorites several times around $4.3 \mathrm{Ga}$, and the Earth cannot have escaped this Late Heavy Bombardment [120-122]. Large impacts sterilized the Earth [123], but ejecta thrown out into space may have contained organisms that returned life to the planet after they fell back ${ }^{3}$ during clement conditions [124,125].

Between large impacts the Earth's surface temperature was the result of a balance between the heat coming in by solar radiation and the heat going out due to Terrestrial radiation. The latter is diminished when infrared radiation emitted at the Earth's surface is absorbed by greenhouse gases such as methane, $\mathrm{CO}_{2}$ and water vapour [126].

The early Sun was $\sim 30 \%$ less bright than today [127] due to a lower internal temperature caused by a higher hydrogen/helium ratio [128]. The early Earth may therefore have been cold and covered with ice [129-131]. Again, frequent meteorite impacts may have melted this ice [129]. On the other hand the early Earth may have been kept warm by the greenhouse gas methane [132] produced by early methanogens that gained free energy from the reaction [133]

$$
\mathrm{H}_{2}+\mathrm{CO}_{2} \rightarrow \mathrm{CH}_{4}+\mathrm{H}_{2} \mathrm{O}
$$

The evidence available in the geological record diminishes as one goes back in time, and it seems hard to decide on a hot or a cold ocean before $3 \mathrm{Ga}$ [134,135]. Early global glaciations have been dated at $2.9 \mathrm{Ga}$ [136] and $2.2 \mathrm{Ga}$ [137] and may have been due to a loss of methane. Because of the constant loss of hydrogen to interplanetary space the Earth's atmosphere must steadily have become less reducing [138]. Oxygen may have been generated by cyanobacteria that possibly emerged at $2.8 \mathrm{Ga}$ [139], i.e., after the $2.9 \mathrm{Ga}$ glaciation. The oxygen concentration in the atmosphere became significant between 2.45 and $2.32 \mathrm{Ga}$ [140]. The first fossils attributed to the eukaryotes have been dated around $1.8 \mathrm{Ga}$ [141], after the $2.2 \mathrm{Ga}$ glaciation, and it is proposed that their progenitors lived during the glaciations on thermosynthesis by the mechanisms described hereafter.

The dark bottom of the ocean may have remained reducing long after $2.2 \mathrm{Ga}[142,143]$. In that case there would often have been no means of primary production by photosynthesis and chemosynthesis in organisms on top of hydrothermal vents at the bottom of the ocean, and often no alternative to thermosynthesis as primary producer. It is often claimed that the thermal gradient of a hydrothermal vent is a potential biological energy source and that it in particular may have driven the origin of life [100,101]:

... heat derived from the hydrothermal cooling of newly-emplaced oceanic crust provides the energy source for converting inorganic precursors into organic compounds.

The gradient may similarly have been a biological energy source during global glaciations. Such biological use of heat as an energy source requires specific biochemical pathways and physiological adaptations, which remain to be identified. The world around us should be explored for these pathways and adaptations that may still be extant but would have remained concealed. They may however also have gone extinct, in which case they would require theoretical and conceptual development. 
In addition to the biological heat engines proposed by this author, few other biological heat engines have been proposed. Sidney Fox drew attention to the role of heat as an energy source during the synthesis of proteinoids from amino acids [116], but nowadays most origin of life investigators seem to consider his approach a dead end in origin of life research; for an exception, see Bahn et al. [115]. A role of heat during the unfolding of ATP Synthase that results in ATP release by the binding change mechanism [145] and during photosynthesis [61] has been proposed by other authors, who did not recognise that the underlying mechanism must concern a heat engine. Matsuno has proposed several heat engine mechanisms [146,147] and has experimentally investigated quenching of a hightemperature chemical equilibrium in a simulation of a hydrothermal vent [148].

In this and following studies we consider in detail heat engine mechanisms based on the chemiosmotic machinery and apply them in models that permit life to survive and evolve at hydrothermal vents in the absence of photosynthesis and respiration.

\section{Between Fire and Ice: Thermosynthesis in a Thermal Gradient (TSG)}

\subsection{Thermal Fluctuations on the Surface of a Hydrothermal Vent}

Since convection above it is plausible, a hydrothermal vent was a suitable niche for early thermosynthesizers that lived on TSC. Convection is self-organizing, and arises in a fluid subject to a temperature gradient when the upward force due to buoyancy - in turn due to the density difference caused by the gradient - overcomes the friction caused by the viscosity of the fluid. Being carried along by convection does not cost an organism energy.

Geysers such as Yellowstone's well known 'Old Faithfull' demonstrate the periodicity of physical processes in volcanic areas; they are good examples of relaxation oscillations [23]. Near a hydrothermal vent thermal cycles with large amplitudes can be expected due to a similar pulsation in the ejected fluids [149]. An additional agent of temperature variation could be turbulence in the water flowing over the vent.

The proposed scenario for the emergence of the thermotether starts with a sessile thermosynthesizer that benefited from these temperature fluctuations upon attachment to the hydrothermal vent. Thermosynthesis in a thermal gradient (TSG) is characterized by ATP generation without the organism being moved by convection.

\subsection{Emergence of the Thermotether: a simple Relaxation Oscillator}

A fluid flow can be characterized by the Reynolds number $R e$, the ratio of inertial and viscous (frictional) forces:

$$
\operatorname{Re}=v L \rho / \eta=v L / v
$$

where $v$ is the speed of the fluid, $L$ a relevant length, $\rho$ the fluid density, $\eta$ the fluid viscosity, and $v=\eta / \rho$ the dynamic viscosity of the fluid [150].

The flow adjacent to the surface of a rigid object is laminar and the flow in the bulk of the fluid turbulent. The area of laminar flow is called the boundary layer, and when the object and the fluid are at different temperatures, this boundary layer comprises most of the temperature difference. The 
boundary layer at the interface between the ocean and a hydrothermal vent is expected to contain a similar thermal gradient.

The edge between the boundary layer and the bulk fluid is not sharp, which makes the thickness $\delta$ of the boundary layer a somewhat loosely defined notion. In the case of a plate parallel to the flow the relation $\delta \approx x / \sqrt{ } \operatorname{Re}$ has been given, where $x$ is the distance to the edge of the plate, and Re the Reynolds number (Figure 9) [151]. The boundary layer therefore starts thin. For Reynolds numbers of $10^{4}-10^{6}$, the boundary layer thickness at $1 \mathrm{~cm}$ from the edge of the plate would consequently be $10^{-4}-10^{-5} \mathrm{~m}$, i.e., $10-100 \mu \mathrm{m}$.

Figure 9. Boundary layer above a plate in a flowing fluid. The flow is laminar within a distance $\delta$ from the plate; $\delta$ increases with the distance $x$ to the edge of the plate.

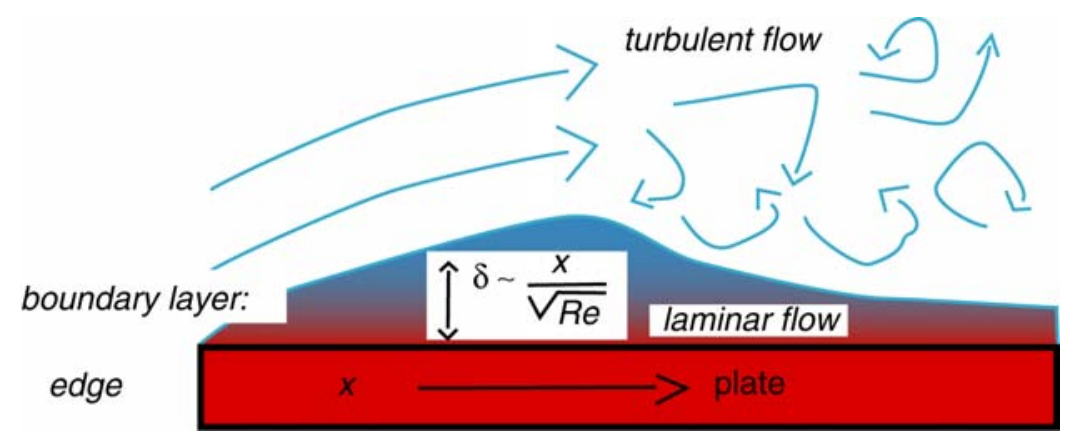

Proposed mechanism of the thermotether Because active movement in a viscous fluid is dissipative, it would cost an organism of the size of say $1 \mu \mathrm{m}$ much energy to move inside the boundary layer [150]. For a smaller organism, movement becomes even more difficult because of the lower value of the Reynolds number: below the scale of bacteria all movement is strongly overdamped [152], and instigating active biological movement on this scale seems impossible. But in general, biological phenomena start small-either during the life cycle of the organism or during speciation - and then increase in size. How did active biological movement emerge when it could not start small? This study proposes: Active biological movement emerged upon the 'kinetic takeover' by life of movement that resulted from thermal conformation changes driven by relaxation oscillations in the thermal gradient above a hydrothermal vent.

In the proposed scenario the vent-attached microorganism acquired a flexible tether [153] that permitted the microorganism to move at random in the medium near the vent. This random movement enhanced the amplitude of the experienced thermal cycling, which increased the free energy generated by thermosynthesis.

In the next evolutionary step the flexible tether turned into a self-actualized protein engine that cyclically changed conformation in the thermal gradient by making use of cold denaturation, the unfolding of a protein at low temperature around the freezing point of water $[23,25]$.

When the so defined 'thermotether' extended into the cold beyond the boundary layer it contracted due to the unfolding. After shortening, it found itself near the hot substrate, and extended again. At no cost of free energy for the organism, this relaxation oscillation thermally cycled the FPs that the

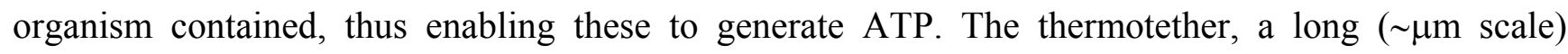
filamentous protein, had taken over the role of convection. This relaxation oscillation requires a delayed adaption by the protein to the equilibrium conformation at the local temperature; the delay 
may be due to the time required for diffusion in conformational space [154] and may also be associated to co-movement of water with the protein [155].

The capability of making use of a static thermal gradient opened up areas at a larger distance from the vent as habitat, where fluctuating temperatures were absent. It would have been advantageous when the length of the thermotether increased so that it spanned the entire thermal gradient across the boundary layer. Because of the linear increase of the boundary layer with the distance to the edge (Figure 9) the thermotether could gradually increase in size and the organism its distance to the edge [156] during evolution.

The presence of a thermotether supposes export of synthesized proteins through the cell membrane. The involved translocation capability must be old. It has been proposed that a first ribosome worked on thermal cycling [4,5], and this may also have been true for the first protein exporter. Today, export makes use of translocon protein complexes [157]. Hereafter protein export will be associated with the type III secretion machine; the related hollow bacterial flagellum can internally transport monomers of its constituting protein to its tip [158-162].

Implications There have been few studies of heat engines consisting of protein. It has been proposed that a macroscopic engine constructed of collagen that operated on a salt concentration difference also would work on a temperature difference [163].

Any spatially extended biological structure could have functioned as a thermotether, even an entire organism could. Filamentous structures that may be microfossils are ubiquitous and date back as far as $3.5 \mathrm{Ga}$ [164]. Moreover, [165]:

... all of the microfossils associated with ancient hydrothermal deposits reported to date are filamentous.

These filamentous fossils resemble today's prokaryotic cyanobacteria, but it has been recognized that this morphology does not imply a photosynthetic physiology [166]. Fossils of long filaments (0.5-2 $\mu \mathrm{m}$ wide, up to $300 \mu \mathrm{m}$ long) are also found near the 3,235 Ga old remains of hydrothermal vents [22]. The filaments may even have been caught frozen while functioning as thermotether [22]:

Perhaps most significantly, the changes in preferred orientation of filaments in different areas . . . may indicate behavioural variations in different micro-environments, a distinctly biological feature. Similar patterns are evident in modern microbial mats . . . and hot-spring communities ... indicating a biotic tropism or taxis in response to a gradient or fluctuation in a salient ecological parameter.

Today's hydrothermal vents could be explored for the presence of organisms with thermotethers, and the ubiquitous filamentous organisms especially [165] investigated for TSG capability. Organisms can live on the oxidation of basalt [167] and respirers may easily win the competition with thermosynthesizers where the water of the ocean is oxygenated. Such competition may be absent near those hydrothermal vents where the natural water is anoxic: examples are intermediate depths of the ocean near the Pacific coasts of the Americas, of Namibia and in the Black Sea, Baltic Sea and the Arabian Sea [168]. Here large filamentous bacteria are common. In many of these places organisms that respire will use oxidants different from oxygen, such as sulphate, but in some places a redox 
equilibrium that would impede all respiration is plausible that would give room for thermosynthesizers. If present day TSG organisms could be found, their isotopic footprints such as their ${ }^{13} \mathrm{C} /{ }^{12} \mathrm{C}$ ratio should be determined. An isotopic footprint distinct from photosynthesis could link TSG to the oldest fossils, which show very low ${ }^{13} \mathrm{C} /{ }^{12} \mathrm{C}$ values ( - 30\%o) [169].

Life started small. During TSC there is no evolutionary driving force towards larger size. On the contrary, being small has the advantage of a fast heat exchange between the organism and its local environment. Moreover, due to the small size moreover no internal transport mechanisms are needed [170]. Nowadays not all bacteria are small. In high-nutrient media, where there is no diffusion limitation, very large bacteria exist. In the gut of tropical fish bacteria as large as $80 \times 600 \mu \mathrm{m}$ are reported [170]. In TSG a large size has the advantage that a larger part of the thermal gradient is spanned. Most interestingly, hydrothermal vents [171-174] and low-oxygen areas of the ocean [168] contain today some of the largest bacteria known.

The quickly-contracting spasmoneme of the protist Vorticella rotates during its $\mathrm{Ca}^{2+}$ induced contraction [174]. Such an effect of $\mathrm{Ca}^{2+}$ can be interpreted as a lowering of a thermal transition temperature, i.e., as a way to mimic an increase in temperature while the temperature remains constant [85]. The relationship between temperature-induced contraction and rotation suggests the possibility of modelling the emergence of the rotating bacterial flagellar motor in terms of the thermotether as well.

\section{The Flagellar Motor, the Flagellar Pump, the Flagellar Ratchet and the Flagellar Computer}

Heat dissipation by heat conduction in a thermal gradient is intrinsic to the thermotether. The proposed oscillating thermotether is therefore related to non-equilibrium thermodynamics $[175,176]$, just as thermoelectricity, thermal diffusion and the thermal diffusion potential. Requiring only two components, the thermotether and the $\beta$ subunit of ATP Synthase, the free energy generating machinery is simple, but the energy conversion efficiency - the ratio of the free energy produced by TSG and the heat transported from high to low temperature - can only be very low. In an early thermotether-based organism there was room for improvement towards higher efficiency, larger complexity and use of smaller thermal gradients.

Movement by protein conformational changes driven by thermal cycling is not subject to impediment by a low Reynolds number. In contrast, it is hard to account for the overdamping of motion on the molecular scale in models that do not make use of thermal cycling [152]. In our model, the thermally induced thermotether folding/unfolding would occur concomitantly [177] with binding/unbinding of nucleotides in the subunits of the $\mathrm{F}_{1}$ moiety during reversible ATP hydrolysis and synthesis. Although the thermotether as a whole must function irreversibly, some partial processes can have approached reversibility during evolution.

Previous studies [4,5] demonstrated that invoking thermal cycling opens up new possibilities in the modelling of early evolution. We now consider additional constructs derived from the thermotether: a second model for ATP Synthase, and models for the emergence of the 'flagellar pump', the flagellar motor, and the 'flagellar ratchet', a biological analogue to Feynman's ratchet mechanism [27]. The information processing capabilities of a bacterium can be related to the flagellar motor, and the obtained 'flagellar computer' is compared to the Turing machine [31]. 


\subsection{Emergence of ATP Synthase in a Thermal Gradient}

A previous study has given a scenario for the emergence of an ATP Synthase with a temperaturedependent $\mathrm{H}^{+}$/ATP ratio: Figures 7 and 8 in reference [4]. In the scenario a proton translocator is added to a progenitor of the $\alpha$ subunit in $F_{1}$, and this translocator is pushed/pulled across the membrane during conformational transitions in the $\alpha$ subunit between strong and loose ATP binding (Figure 10). A variation in membrane thickness [178] with the temperature, plausible during a thermotropic phase transition in the membrane, occludes a proton binding site of the translocator during part of the thermal cycle. This occlusion leads to the pumping of protons, and the resulting proton gradient permits the import of nutrients. The addition to the proton pump of the $\beta$ subunit that could exchange nucleotides yields an ATP Synthase with a temperature-dependent variable $\mathrm{H}^{+}$/ATP ratio as pictured in Figure 8 . Figure $3 \mathrm{~b}$ shows how the combination of a proton pump and ATP Synthase generates ATP.

Near the surface of high-temperature hydrothermal vents the $\mathrm{pH}$ is low, near low-temperature vents the $\mathrm{pH}$ is high [179]. From a steep $\mathrm{pH}$ gradient free energy can be gained in a simple way. An ATP Synthase-containing vesicle that was cycled between two different pHs could generate ATP by what we call the 'Jagendorf mechanism': after the internal $\mathrm{pH}$ has equilibrated with the external $\mathrm{pH}$, a decrease in external $\mathrm{pH}$ after a movement driven by the thermotether results in ATP synthesis [180] (Figure 11).

The $\mathrm{pH}$ gradient may also have played a role during the emergence of the thermotether and ATP Synthase. The protein unfolding temperature typically depends on the $\mathrm{pH}$ [181], and a thermotether can gradually have gained the ability to oscillate in a combination of a thermal and $\mathrm{pH}$ gradient, and eventually to oscillate in a $\mathrm{pH}$ gradient only.

Figure 10. Previously proposed mechanism for a proton pump that worked on thermal cycling. During a thermal cycle a thermotropic phase transition caused variation in the thickness of a biomembrane, which occluded a proton binding site in a protein that was translocated across the membrane. The translocation was driven by conformational changes in an FP between strong and loose nucleotide binding. From [4].

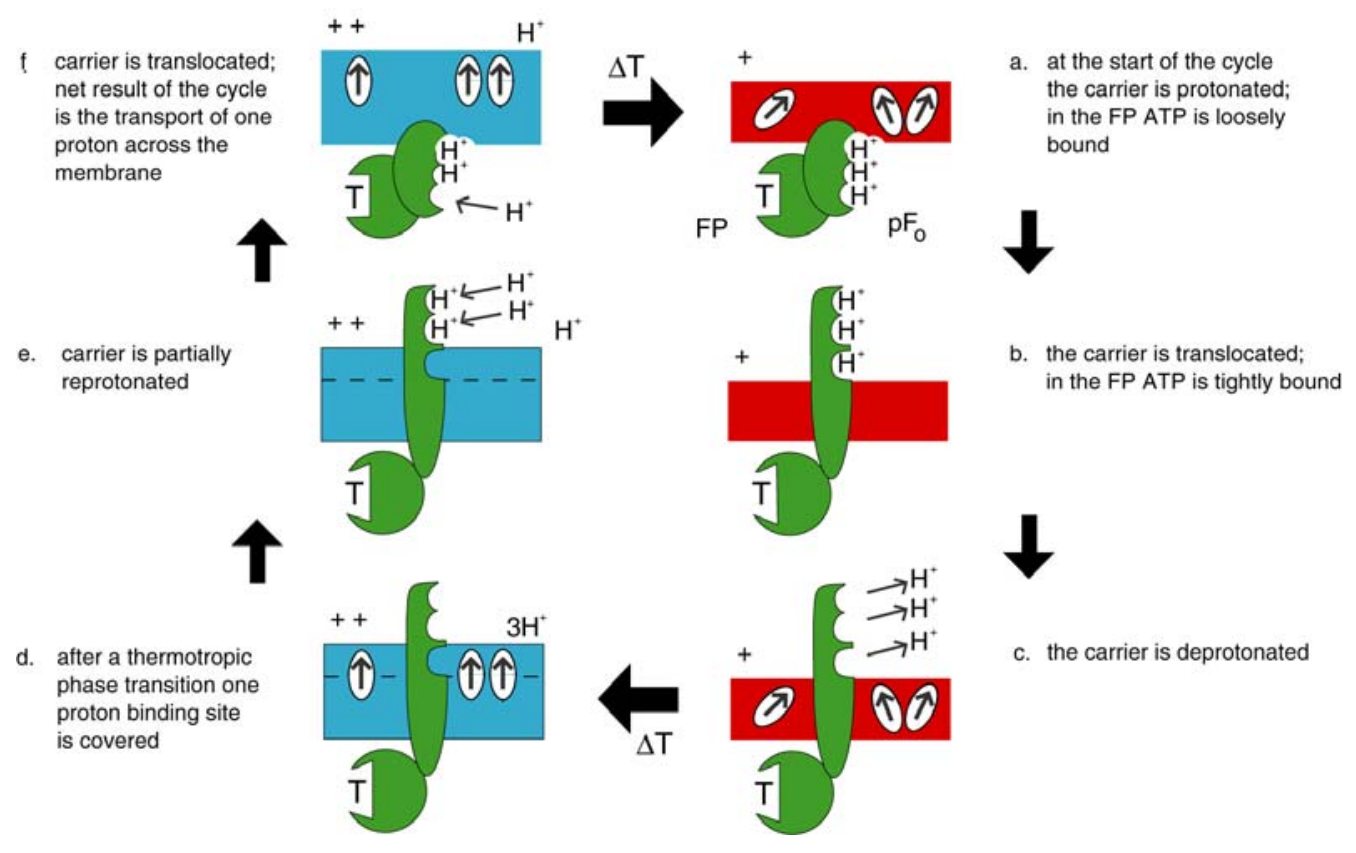


Figure 11. Proposed Jagendorf mechanism. Near a hydrothermal vent a $\mathrm{pH}$ gradient is present. During a thermotether driven oscillation the external $\mathrm{pH}$ of a cell will therefore vary. ATP could be gained from this $\mathrm{pH}$ variation, when ATP Synthase is only active at high temperature, with the cell near the vent: ATP is synthesized while protons enter the cell. These protons leave again later by conduction through the cell membrane, when the cell is at its largest distance from the vent, where the external $\mathrm{pH}$ is high.

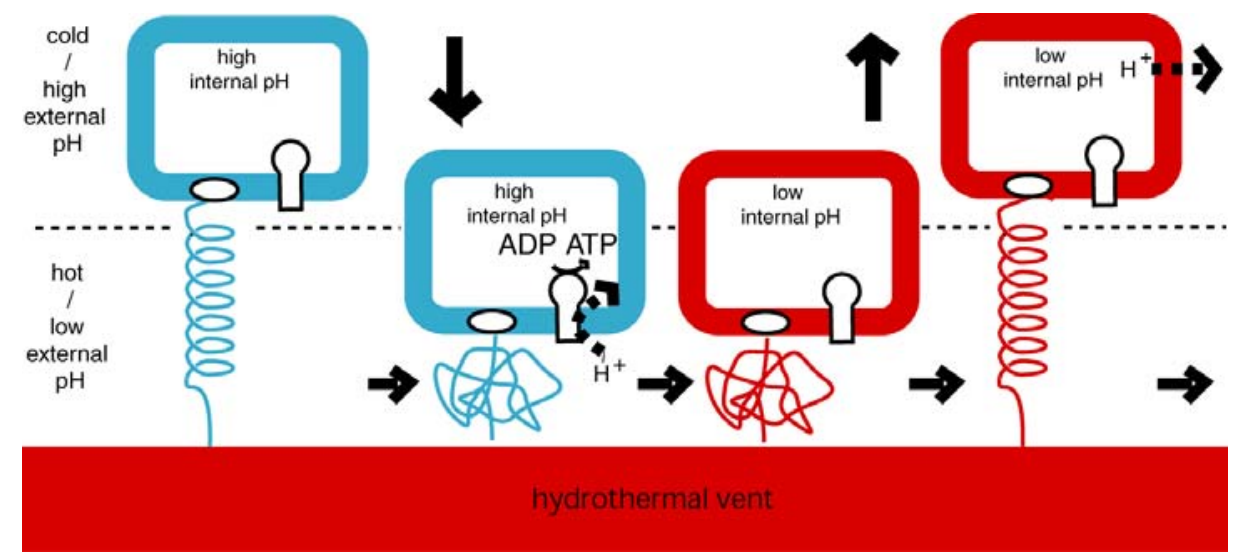

Figure 12. A proton pump based on the thermotether. Instead of using a variation in biomembrane thickness as in Figure 10, a conformational change is invoked in a protontranslocating protein resembling the thermotether. This protein, which also resembles the $c$ subunit in ATP Synthase, was anchored in the periplasm. (a) $\rightarrow$ (b) At low temperature, the acid residue A-H loses its proton to the periplasm. The proton has been transported. The base residue B stays behind. (b) $\rightarrow$ (c) The temperature increases. The cold-denatured protein folds, but it cannot instantaneously assume its equilibrium shape - its (compression) strain is indicated by the asterisk. (c) $\rightarrow$ (d) While the protein extends, the base residue $\mathrm{B}$ is positioned in front of the inner proton channel leading to the cytoplasmic space. (d) $\rightarrow$ (e) At high temperature the base residue B is protonated along the proton channel from the cytoplasm: the acid residue $\mathrm{A}-\mathrm{H}$ is formed. (e) $\rightarrow$ (f) The temperature decreases. Unfolding at low temperature yields a strained protein in tension. $(\mathrm{f}) \rightarrow(\mathrm{g})$. The cycle closes when the protein relaxes to its cold-denatured equilibrium state. The acid residue A-H moves in front of the proton channel leading to the periplasm side, and the cycle is closed.
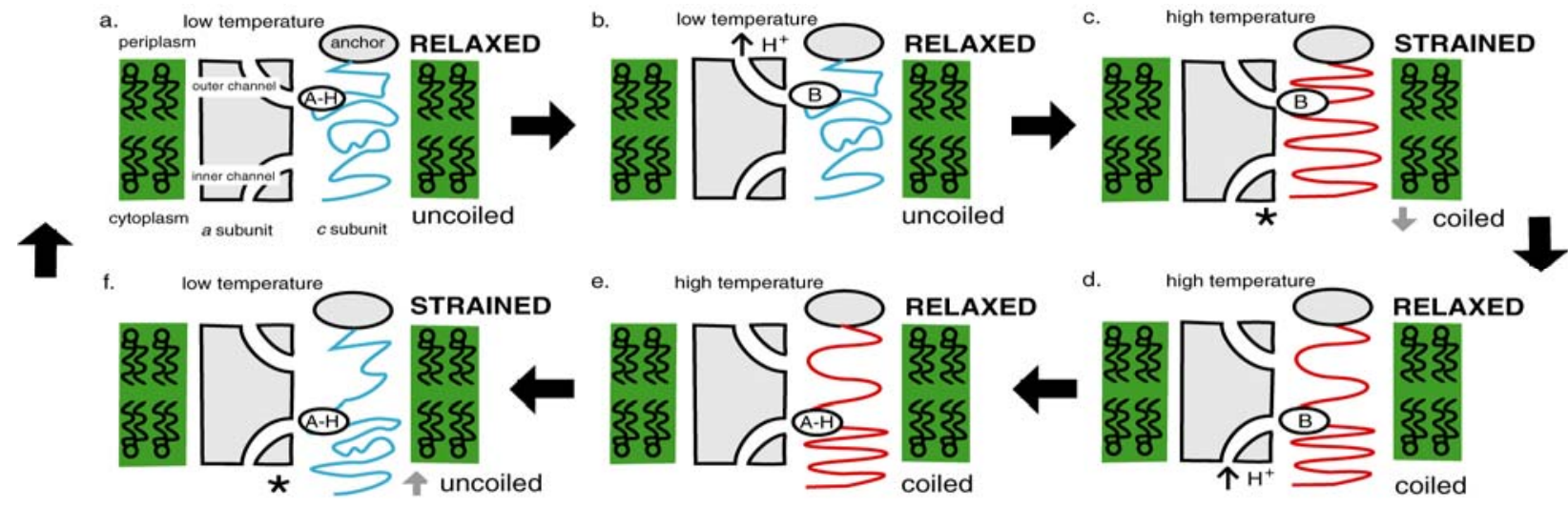
The second scenario for the emergence of a proton pump with the same components as ATP Synthase is based on the recently found aqueous proton channels through ATP Synthase's subunit $a$; these lead to the proton carrying Asp-61 residue in the $c$ subunit of $F_{o}[182,183]$, which can undergo a conformation change [184,185]. The $\mathrm{F}_{\mathrm{o}}$ moiety of ATP Synthase contains 10-15 of these $c$ subunits [185]. In the second scenario the conformation change drives a proton pump (Figure 12), just as in the first scenario described in Figure 10. No use is made of occlusion by membrane thickening: the key step is performed by proteins instead of by lipids.

A significant $\mathrm{pH}$ difference across a membrane is common, and is concentrated across it, as protons freely diffuse in water but not through a lipid membrane. ${ }^{4} \mathrm{~A} c$ subunit that oscillates on a $\mathrm{pH}$ gradient across a biomembrane (Figure 12) could have evolved from a thermotether adapted to oscillating in this $\mathrm{pH}$ gradient. This mechanism may still play a role in today's ATP Synthase: the strain generated in the $c$ subunit would release the tightly-bound ATP in the $\mathrm{F}_{1}$ moiety, constituting the conformational energy transduced from $F_{o}$ to $F_{1}$ depicted in Figure 1 .

It is proposed that the flagellar pump emerged during evolution when similar proton-transferring proteins attached to a protein export apparatus, and caused this apparatus to pump protons and later to rotate, or, in a slight twist of this idea, that the protein export apparatus itself extended and started to function as a thermotether and later as flagellum.

\subsection{Today's Flagellar Motor}

Before we consider the emergence of the flagellar motor [187], we sketch its structure (Figure 13) and function. It consists of many proteins and is still the subject of extensive research, since:

'... we do not know how the motor actually works ...' [30]. Although its present day functioning has not yet been completely resolved, we already model its emergence.

The motor is important. In Escherichia coli the flagellin protein FliC of the rotating helical filament comprises $8 \%$ of the bacteria's total protein [188]. During the growth of the flagellum, monomers of FliC move through the hollow flagellum to its tip by an ATP dependent process $[189,190]$. This movement is similar to protein export and we already referred to the large resemblance of the core of the flagellar motor to the type III protein export apparatus [162-166]. The FliI component of the flagellar motor [191] is homologous to the $\alpha$ and $\beta$ subunits of ATP Synthase [30].

The rotation rate is several hundred $\mathrm{Hz}$ [30], about the same turnover frequency as ATP Synthase. Effecting movement does not require a particular shape of the flagellum. At low Reynolds numbers, anything rotating will do [150]:

The interesting question is not how they swim. Turn anything - if it isn't perfectly symmetrical, you'll swim. 
Figure 13. Today's flagellar motor (E. coli) and some of its proteins. The rotating flagellum has a length of $\sim 1 \mu \mathrm{m}$. The flagellum consists of a hook and a filament of FliC monomers; growth occurs by addition of FliC monomers that have moved through the hollow flagellum to the tip. The transport apparatus sends the FliC monomer across the cytoplasmic membrane. EM pictures show several rings in the cell wall. The P-ring in the peptidoglycan is associated with the stator of the motor and is connected to the MotA/MotB protein complex. The MotB protein contains the residue involved in proton translocation and is part of the MS-ring in the inner membrane. The C-ring consists of the FliM and FliN proteins. The FliG-FliM-FliN complex implements inversion of rotation direction.

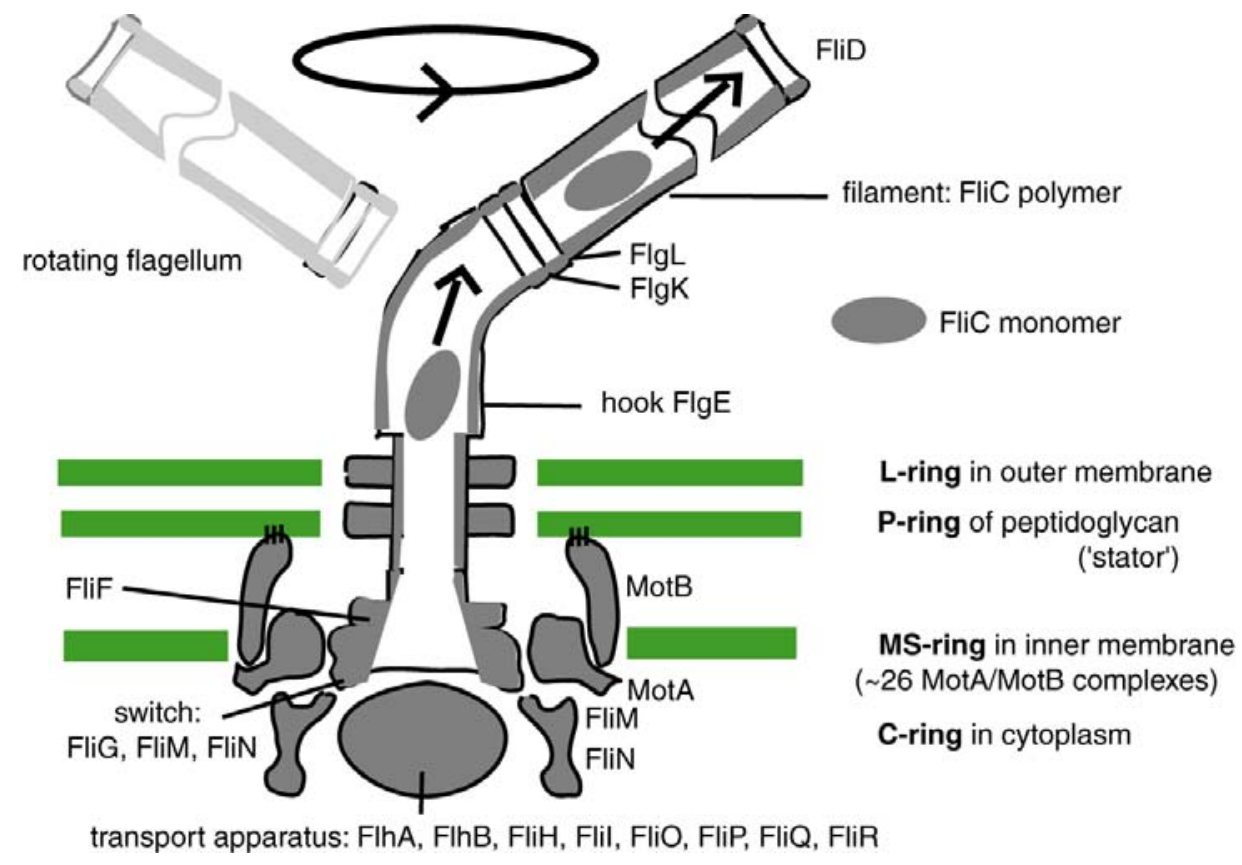

A key question in the emergence of the motor is therefore the origin of torque, which is associated with the proton-translocating MotA/MotB proteins that are anchored to the cell wall. FliG couples the MotA/MotB proteins on the stator to the rotor. Whereas bioenergetic processes as a rule are driven by ATP, the motor is driven by the PMF, just as ATP Synthase [192]. It has already been mentioned that when the PMF consists of a $\triangle \mathrm{pH}$, ATP synthesis by ATP Synthase is endergonic [71], and this is true for the flagellar motor as well [193].

Another important question is the mechanism of the control of the directed movement. During chemotaxis the bacterium 'runs', i.e., swims steadily in one direction; then it 'tumbles', performs rotation diffusion, and then 'runs' again in another direction. When the new direction is advantageous, the next 'tumble' is delayed, otherwise it is advanced [194]. Flagella in E. coli are bundled and move as a whole. Tumbling occurs when a single flagellum upsets the bundle by temporarily switching between rotating clockwise $(\mathrm{CW})$ and counter clockwise $(\mathrm{CCW})$, 'as viewed along a filament from its distal end toward the cell body' [30]. The 'switch complex' consists of FliG, FliM and FliN [195,196]. 


\subsection{The Flagellar Pump}

Proposed emergence Microorganisms are easily tethered to substrates by their flagella [187]. In the proposed model for the emergence of the flagellar motor, its progenitor was a flagellar proton pump that worked on thermal cycling (Figure 3c). The protons generated ATP when they returned through an ATP Synthase. Proton translocation may have been assisted by torque generated in the thermotether during thermal cycling; rotation in one direction would have been obtained by connecting a ratchet and pawl, or in short, a ratchet (Figure 14) to the flagellum that functioned as axis.

Figure 14. (a) Asymmetry in a ratchet-and-pawl mechanism. Sliding of one surface over another is permitted in one direction only. A pawl sticking out from inside the top surface falls into an asymmetric notch in the bottom surface. (b) The inclined plane inside the notch can push the pawl back when the lower surface moves to the right with respect to the upper surface. (c) When the surfaces moves in the opposite direction, the vertical plane inside the notch catches the pawl, and halts further movement to the left.

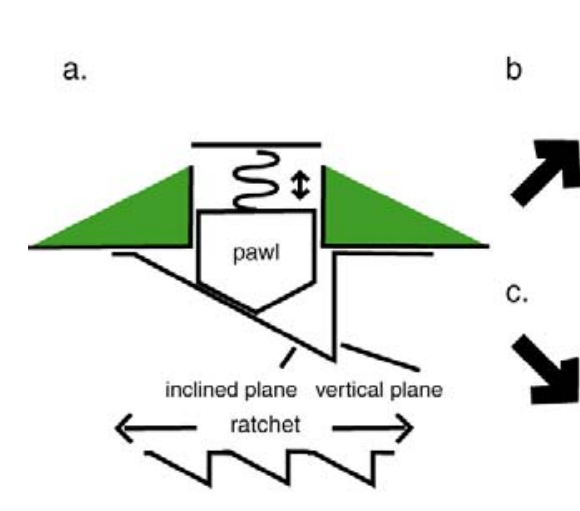

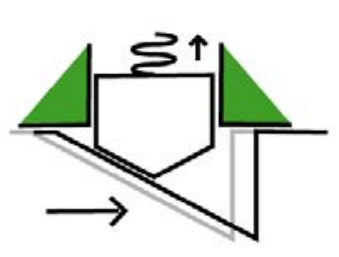
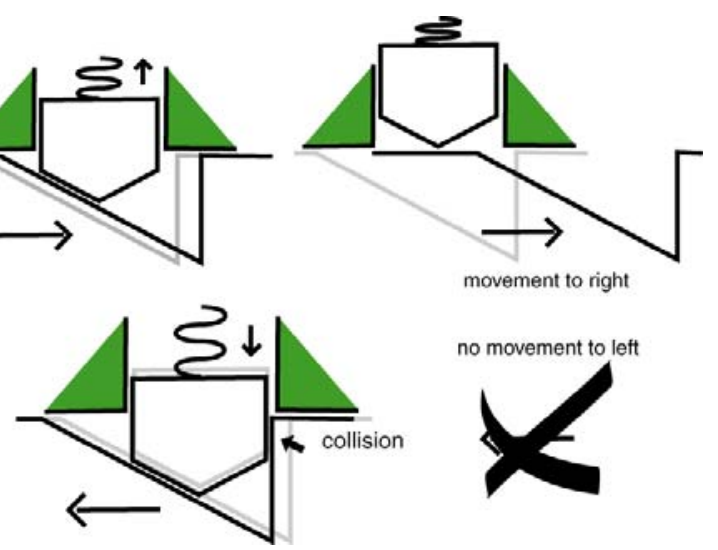

The first flagellar pump may have contained parts taken from ATP Synthase when this acted as proton pump: multiple proton-donating units ( $a$ subunit), and multiple proton translocators ( $c$ subunit) would have been attached to the inner surface of the ring that functioned as a stator and evolved into today's MotA/MotB protein (Figures 15 and 16) with its Asp-32 residue that carries the translocated proton. The MotA/MotB protein combination indeed shows conformational changes [197-199] during proton translocation and could have applied torque to the type III protein export apparatus [161] that constituted the rotor.

Thermotaxis is common in bacteria; some move towards a heated wire [200]. E. coli aggregates in a thermal gradient [201]. It should be observable whether microorganisms that show thermotaxis towards a heated wire attach their flagellum to it and pump protons while the flagellum oscillates in the

thermal gradient.

\subsection{Switch to Isothermy: Emergence of the Flagellar Motor}

The model for the emergence of the flagellar motor starts with a dissipative system: while heat moves from high to low temperature in a thermal gradient, oscillations driven by the thermal gradient 
in protein subunits enable a flagellar pump to function. During a glaciation, evolution maximized the efficiency of the flagellar pump, which initially was very low but eventually reached reversibility, at least for some partial steps of the mechanism - the pumping mechanism being an intrinsically dissipative process, overall reversibility was out of reach.

The return of reductants and oxidants generated by photosynthesis after the end of the glaciation again enabled regular proton pumping by respiration. It could have been effected by endosymbiosis with a respirer or by the formation of a chimera involving a respirer. Proton pumping by the flagellar pump then became redundant; instead, the newly available protons caused the pump to reverse and to co-adapt it as the flagellar motor. Upon disconnection of the tether from its substrate, it started to function as a flagellum while contracting and rotating (Figure 3d, Figure 17).

Figure 15. Overview of the proposed flagellar pump, a progenitor of the flagellar motor. During the thermal cycling sustained by the thermotether the MotB protein takes up protons from the cytoplasmic side of the membrane and sends them across the membrane (details are given in Figure 16). Thermal cycling may in addition have rotated a ratchet that assisted in the back-and-forth translocation of the MotB protein. It moreover may have occluded the entry to the inner proton channel in the MotA protein.

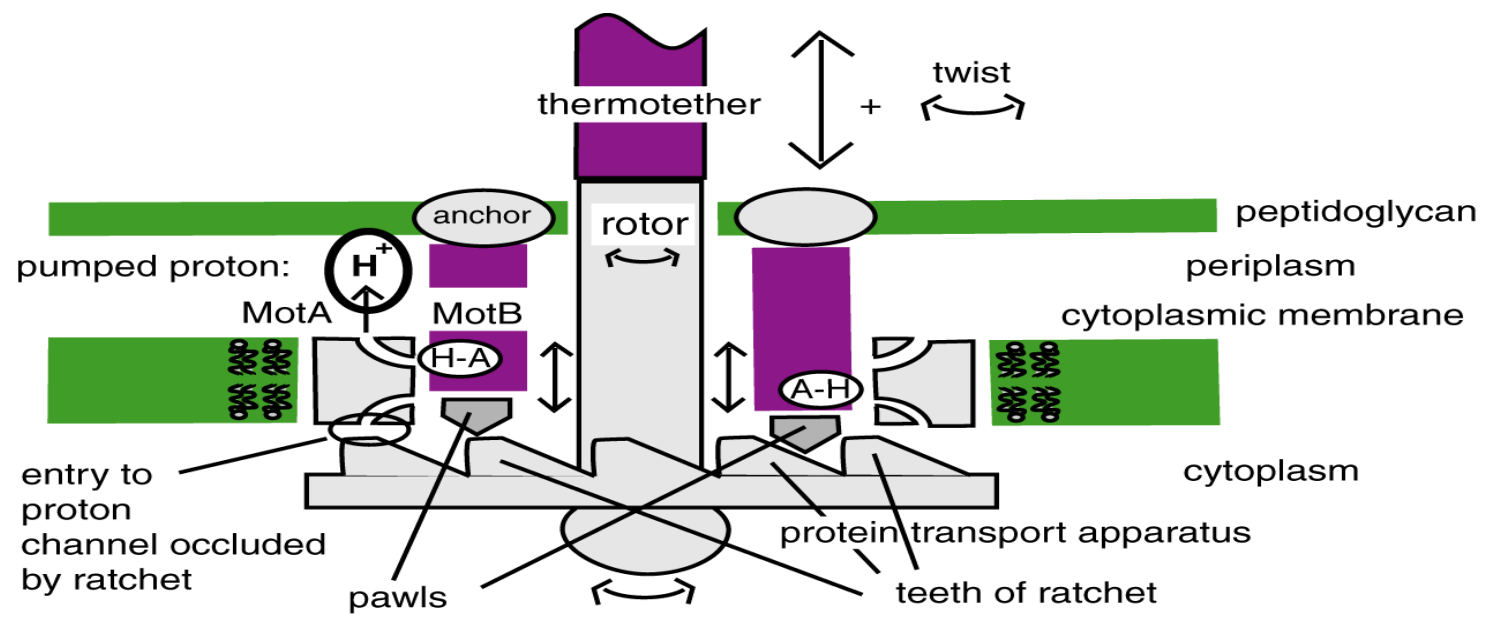

Sequence data show that [202]:

core components of the bacterial flagellum originated through the successive duplication and modification of a few, or perhaps, even a single, precursor gene.

and

The earliest proteins are proximate to the cytoplasmic membrane with later proteins situated distally, first spanning the outer membrane and then giving rise to structures (i.e., the hook, junction, filament, and capping proteins) that extend outside of the bacterial cell. Thus, the flagellum represents a case whereby its order of assembly recapitulates its evolutionary history. 
Figure 16. Cycle of the proposed flagellar pump. Proton translocation involves the MotB progenitor protein. Ratchet-and-pawls have been added to the mechanism of the proton pump described in Figure 12. The MotB protein is anchored to the peptidoglycan membrane in the periplasm and the moving 'pawl' is situated in the cytoplasm. (a) $\rightarrow$ (b) At low temperature, the acid residue A-H loses its proton to the periplasm through the outer proton channel in the MotA protein; the base residue B remains. (b) $\rightarrow$ (c) The temperature increases. The cold-denatured MotB folds and assumes a strained (asterisk) compressed configuration. (c) $\rightarrow$ (d) MotB lengthens. The base residue B moves in front of the inner MotA proton channel that leads to the cytoplasm. The pawl hits the sliding plane of the notch in the ratchet, pushing the ratchet to the left. (d) $\rightarrow$ (e) Still at high temperature the base residue $\mathrm{B}$ of the extended and folded MotB protein is protonated from the cytoplasm side along the proton channel, forming the acid residue A-H. The pawl pushes the ratchet so far to the left that it occludes the proton channel. The ratchet halts when the pawl hits the vertical plane inside the notch. (e) $\rightarrow$ (f) The temperature decreases. Unfolding at low temperature yields a strained MotB protein in tension that contracts. (f) $\rightarrow$ (a) The cycle closes when the MotB protein relaxes to its cold-denatured equilibrium state. The residue with the base residue $\mathrm{B}$ is positioned in front of the proton channel leading to the periplasm. The ratchet has lost contact with the pawl and can diffuse freely in both directions.

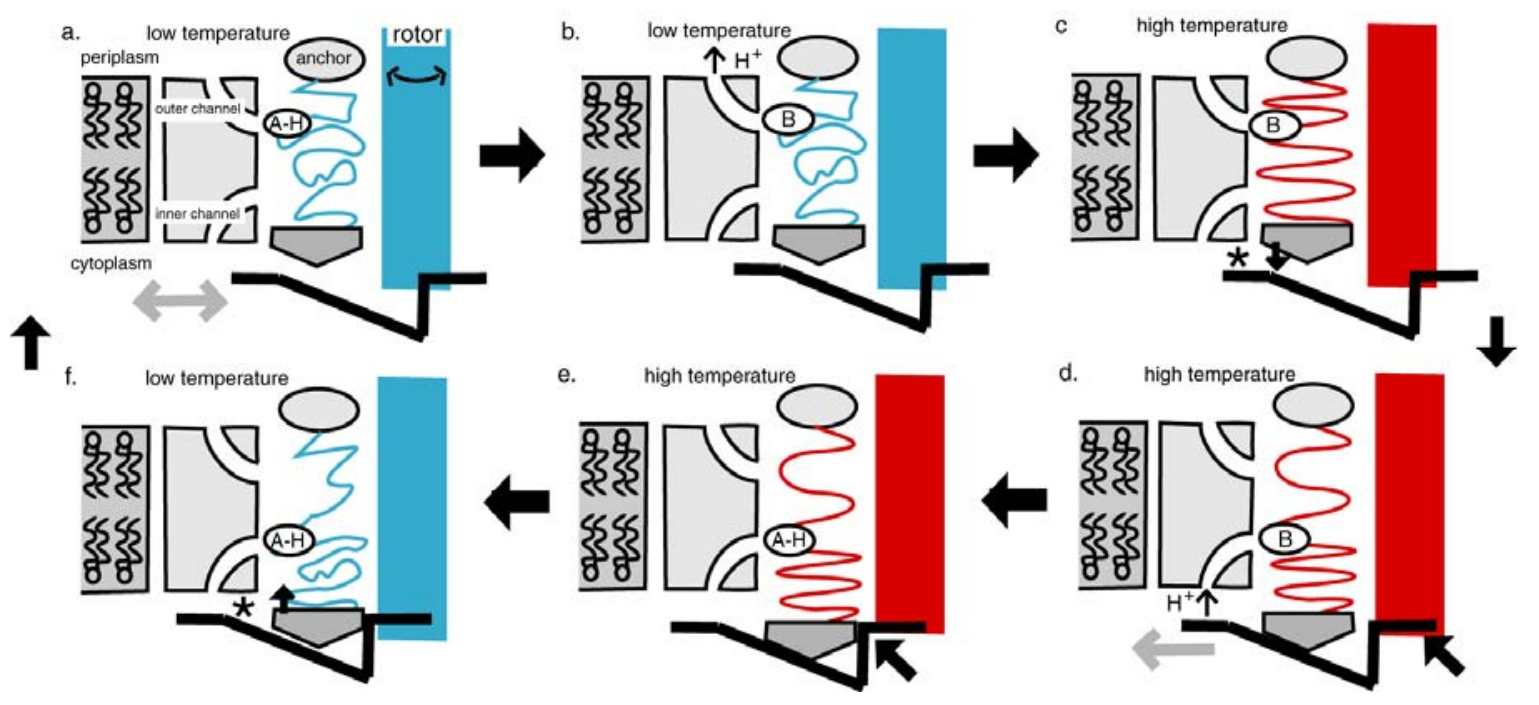

At low temperature CW is the preferred state, at high temperature CCW [203,204]. This study interprets this temperature effect as a possible relic of the flagellar pump. Its flagellum/thermotether rotated $\mathrm{CCW}$ upon contraction after a temperature decrease and $\mathrm{CW}$ upon expansion after a temperature increase. When the flagellar pump reversed, and started to function as a flagellar motor driven by the PMF, this would have caused the flagellum to change orientation as well, i.e., to rotate $\mathrm{CW}$ at low temperature and $\mathrm{CCW}$ at high temperature. 
Figure 17. Proposed cycle of today's flagellar motor. The cycle is the reverse of the cycle of the flagellar pump. In addition, the MotB protein undergoes conformational change by protonation instead of by a temperature change. (a) $\rightarrow$ (b) The base residue B takes up a proton from the periplasm and forms the acid residue A-H. (b) $\rightarrow$ (c) The MotB protein folds and assumes a strained, compacted conformational state, indicated by the asterisk. (c) $\rightarrow$ (d) MotB expands. The acid residue moves in front of the inner channel of the MotA protein. The pawl makes contact with the sliding plane in a notch of the ratchet, forcing the ratchet to the left until the pawl collides with the vertical plane in the notch of the ratchet. (d) $\rightarrow$ (e) The acid residue A-H of the extended and folded protein deprotonates along the inner proton channel. (e) $\rightarrow$ (f) MotB unfolds, first to a strained conformation. The base residue $\mathrm{B}$ is positioned in front of the outer proton channel. The pawl loses contact with the sliding plane of the notch in the ratchet. The ratchet can diffuse freely. (f) $\rightarrow$ (a) The cycle closes when MotB relaxes to its cold-denatured, unfolded equilibrium state. The residue with the base residue $\mathrm{B}$ is positioned in front of the proton channel leading to the periplasm.

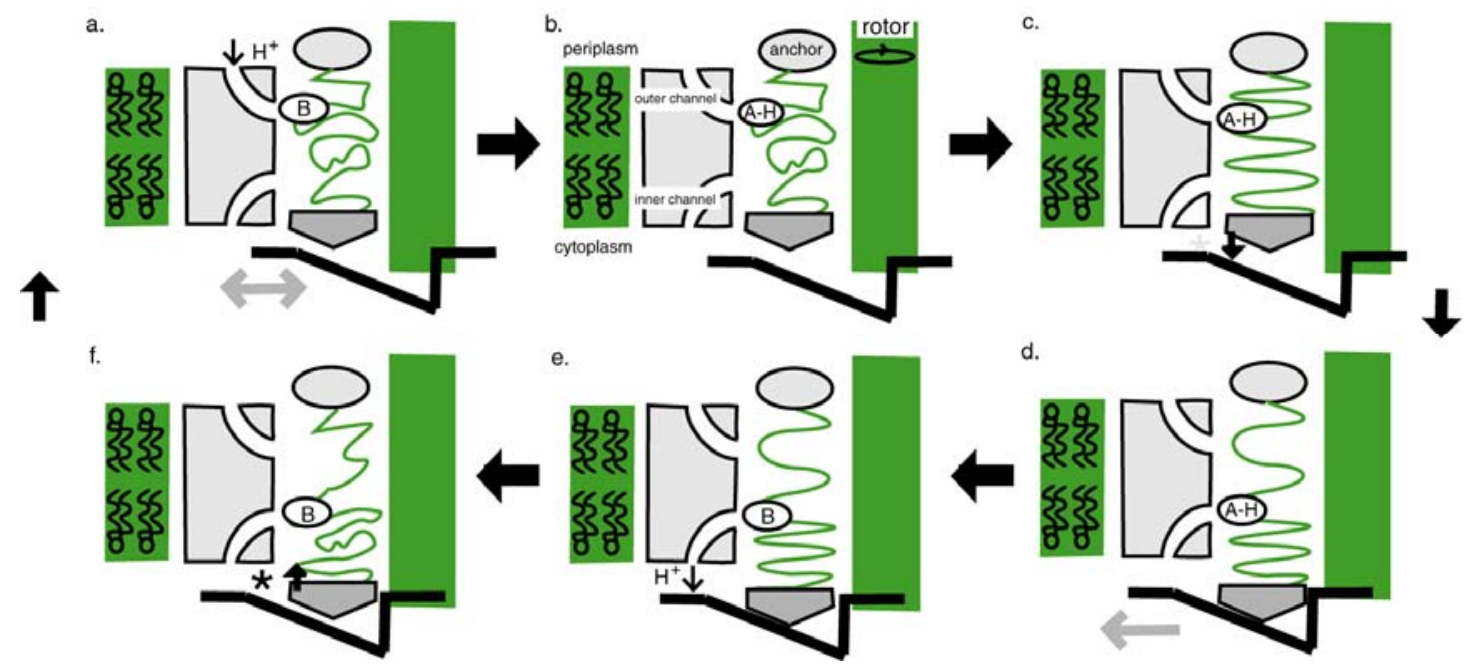

\subsection{The Flagellar Ratchet and Feynman's Ratchet}

We compare the flagellar pump with Feynman's ratchet mechanism for a primitive heat engine [27] (Figure 18). Both the flagellar pump and the Feynman ratchet (1) generate free energy from a temperature difference and contain (2) a structure interacting with the medium (the flagellum resp. the vane), (3) an axle, and (4) a rotor and stator. One difference is that in the pump the axle cyclically contracts, whereas in Feynman's ratchet the axle is rigid. Another difference is that the MotA/MotB proteins in the stator of the flagellar pump are thermally cycled, whereas the pawls in the stator of Feynman's ratchet undergo isothermal fluctuations. 
Figure 18. Feynman's ratchet. The device invokes a ratchet-and-pawl combination in a thought experiment that tries to circumvent the Second Law of thermodynamics [27]. A set of vanes undergoing fluctuating forces due to thermal movements of a gas is connected by an axle to a ratchet-and-pawl. Since the ratchet would only be able to turn in one direction, the axle would turn in one direction as well, and lift the weight at no cost of free energy. Further analysis shows however that the pawl has a finite chance to jump, which would cause the ratchet to fall back. The Second Law remains valid. When the temperature of the vanes is higher than the temperature of the ratchet, the device can however perform external work and lift the weight. It then works as a heat engine. Feynman pointed out that the vanes are set in motion when the vanes have a lower temperature than the ratchet-andpawl. The hot pawl frequently jumps over the barrier during fluctuations and then forces the ratchet to rotate in a direction opposite to its regular rotation.

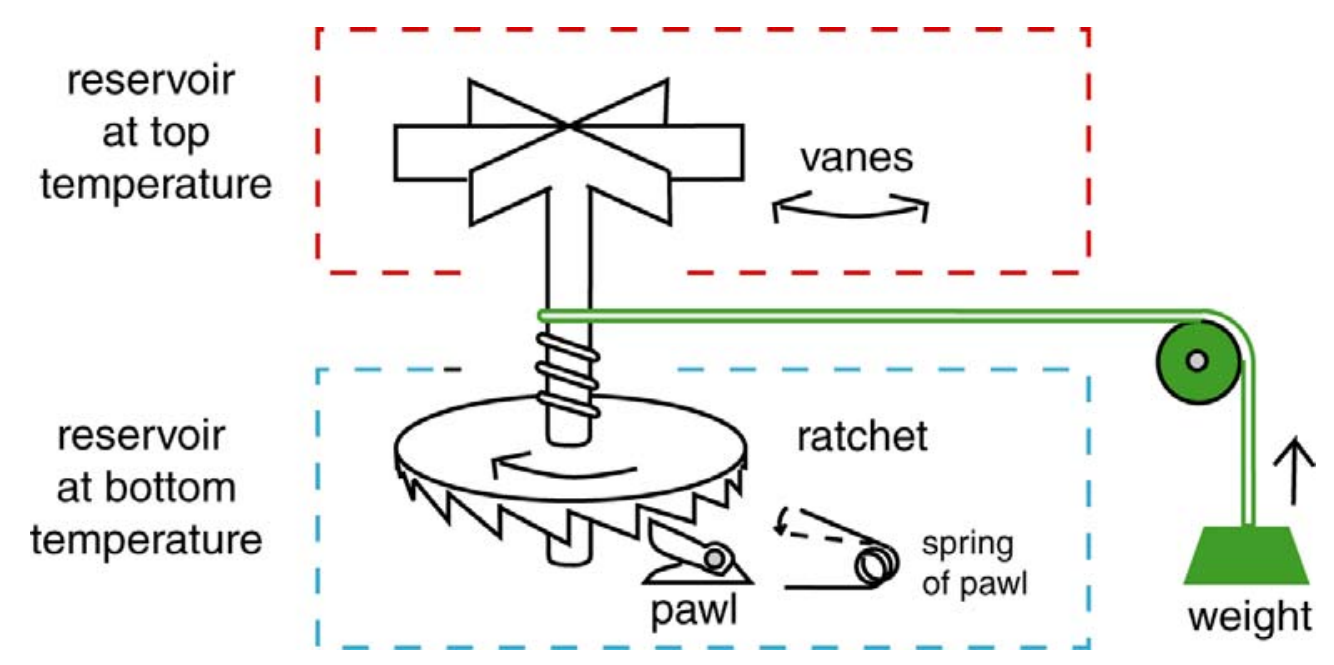

The flagellar pump including its host, the bacterium, is thermally cycled as a whole. In contrast, a thermal gradient is present across the 'flagellar ratchet', a theoretical device that is an analogue to Feynman's ratchet. The MotB protein could be thermally cycled just as in Figure 4. The modifications required for the flagellar pump are:

1. the flagellum must have a higher temperature than the stator/rotor;

2. the thermal fluctuations in the torsion of the flagellum must not become excessively damped during their transfer along the flagellum to the rotor/stator (note that energy transfer by changes in torsion is a plausible means of conformational energy transfer between the $F_{o}$ and $F_{1}$ parts of ATP Synthase as well);

3. the MotA/MotB 'pawl' must undergo significant entropy-decreasing fluctuations in its conformation. Such entropy-decreasing fluctuations have been observed in small macromolecules [205,206].

The flagellar ratchet has several interesting properties. It resembles the recently proposed theoretical 'Brownian gyrator' [207] that rotates in a thermal gradient. Moreover, a sessile organism with a flagellar ratchet could gain free energy not only when the flagellum has a higher temperature than the stator, but also when the flagellum is subject to non-thermal fluctuations or 'noise' (Figure 19). It might even function as a turbine in the presence of a constant current (Figure $3 \mathrm{~g}$ ), ${ }^{5}$ a 
phenomenon that will not occur under the objective of a microscope, because (just as a thermal gradient) the required current is absent there.

Figure 19. The flagellar ratchet. Feynman's ratchet-and-pawl mechanism can function as a heat engine (Figure 18). It is proposed that when the flagellum of a flagellar motor has a higher temperature than the rotor/stator combination, it can similarly to Feynman's ratchet function as a heat engine, which is called a 'flagellar ratchet'. The difference with the flagellar pump is that the pump is thermally cycled as a whole whereas the ratchet is not cycled, and works on the thermal gradient. The free energy gained is used to pump protons across the cytoplasmic membrane. The ratchet could not only work on thermal fluctuations in the flagellum, but also on non-thermal fluctuations, including a constant current.

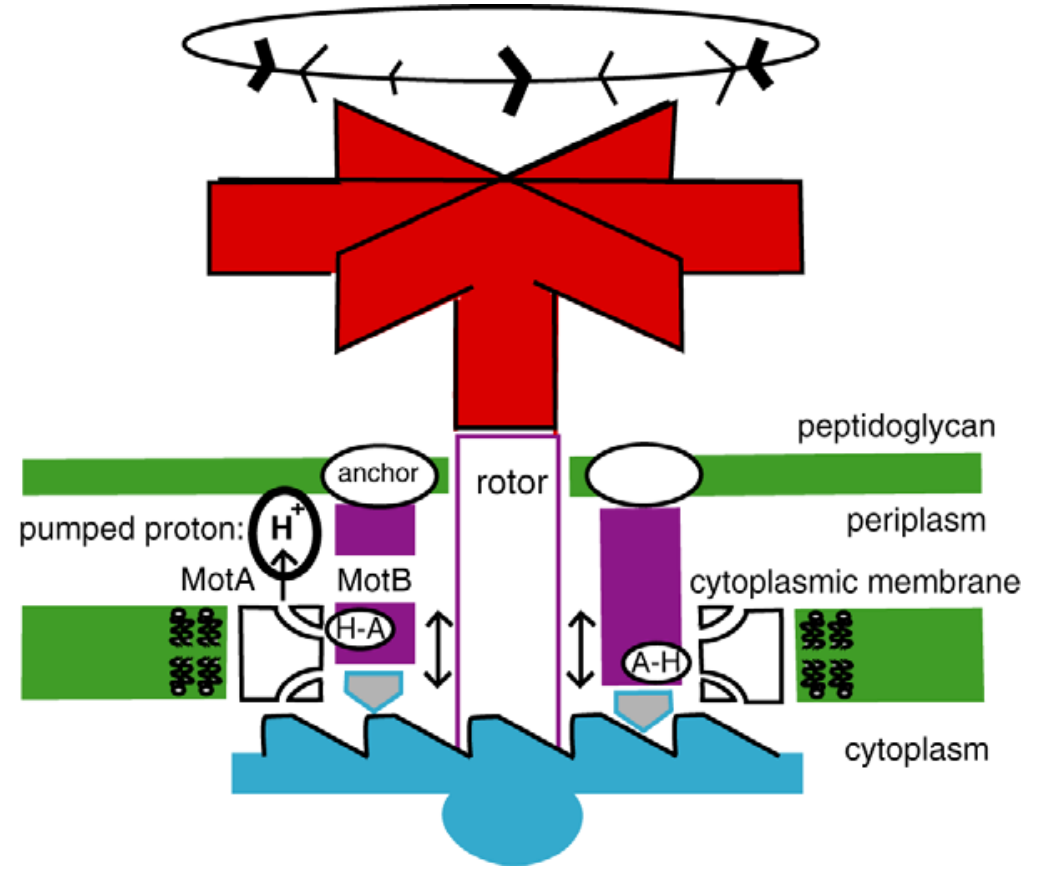

The flagella of many extant microorganisms could be part of a flagellar ratchet. Sessile organisms in environments with a local strong current are considered good prospects. Macroscopic algae such as Laminaria that grow in tidal currents [208] may have emerged from large flagellar ratchets by the acquisition of chloroplasts. Use of flagellar ratchets is an alternative to heterotrophy as energy source in colourless algae [209].

Until the Cambrian, when grazers appeared, the ocean floor was covered with filamentous organisms [210]. Some of these filamentous organisms may, similar to the flagellar ratchet, have gained free energy from the current flow above the ocean floor. In the same way, sessile organisms on the ocean floor of the Jovian moon Europa could, as previously proposed [211], by means of their flagella gain free energy from the uptake of warm vent water in large vacuoles or from the current in the surrounding water. With the flagellum sticking out in the warm vacuole or the moving ocean water, the flagellar ratchet could support both mechanisms.

Other environments of interest include the human body. Near heart valves the flow rate of the blood must be especially high. Because of their pathogenicity, the fastidious bacteria that cause endocarditis [212] are prospects for the presence of a flagellar ratchet. A stimulation of their growth by 
the current flow should be experimentally observable; a dependence could explain their fastidiousness and localization on the valve.

The reversed flagellar ratchet When in Feynman's ratchet the pawls have a higher temperature than the vanes, the pawls set the vanes in motion [27]. A high temperature of the MotA/MotB proteins could similarly cause the flagellum to rotate. This 'reversed flagellar ratchet' must be distinguished from the flagellar pump or the flagellar motor. The organism would not change position - to profit from the thermal gradient it has to remain sessile. When a collection of reversed flagellar ratchets is present on the surface of a cell, a circulation in the water around the collection will be induced. The water circulation required for filter feeding [213] may have emerged from such a collection above a biofilm of microorganisms on top of a submarine hydrothermal vent.

Previously proposed thermal and Brownian ratchets Several studies have been published [215] on 'thermal ratchets' and 'Brownian ratchets', notions also derived from Feynman's ratchet. Therein the ratchet is compared to a periodic potential, and the pawl to a particle moving in this potential [27]. There is some overlap with the ideas presented in this study, although the relevant biochemical context in these previous studies consists of filamentous proteins such as actin or tubulin, the linkage of monomers yielding the spatial periodicity. Some studies investigate the effect of thermal cycling [216-219], similar as proposed here for the flagellar pump. These notions may be relevant for the emergence of contractile proteins and molecular motors.

\subsection{The Flagellar Computer and the Turing Machine}

A flagellated bacterium such as E. coli senses its environment and reacts to it by changing its direction of movement [194]: this information collection and processing, followed by action, demonstrates its cognition capability. A bacterium is a computer. Because the flagellar motor contains all the proteins involved in chemotaxis [30], we consider whether the novel point of view given by thermosynthesis permits an explanation of the emergence and the mechanism of the 'flagellar computer'. ATP Synthase, the flagellar pump and the flagellar ratchet could generate the free energy that a computer in practice requires ${ }^{6}$ [220].

First we consider clocks and temporal periodicity-computation involves repetitive activity. Periodic phenomena must have played a key role during the origin of life [4]. Moreover, any complex and composed system will require synchronization of its parts, which can be implemented by a clock. In today's personal computer, for example, the high-frequency alternating voltage generated by a piezoelectric crystal functions as the clock that synchronizes the parts. A previous study [85] proposed that early thermosynthesizing organisms similarly used thermal cycling to synchronize spatially separated cellular activities. Later in evolution, periodic $\mathrm{Ca}^{2+}$-inflow would have taken over this role of thermal cycling in effecting internal cellular synchrony [85].

It seems most natural to associate gear-containing and dissipative clocks with complex, highly damped rotating devices such as ATP Synthase and the flagellar motor. One flagellar motor complex in a bundle of active flagellar motors could start to function as 'flagellar clock' or flagellar computer, when contact with the other active flagellar motors forces it to rotate and to drive the escapement of a clock. ${ }^{7}$ 
The ratchet in Figure 15 has the same shape as the crown wheel of a verge escapement [223] (Figure 20a). Here the axis of the verge is parallel to the plane of the ratchet. In the anchor escapement the axes of the anchor and the rotor are parallel (Figure 20b). In a flagellar motor a similar back and forth movement could occur and might be coupled to a biological clock. Several authors have proposed escapement mechanisms in biological motors [224-226]. Chemotaxis involves the delay or acceleration of tumbling. It is plausible that the emergence of the bacterial flagellar computer started by the similar delay or acceleration of a flagellar clock.

A Turing machine is a theoretical, mathematical device first used to investigate the limits of algorithms, or more generally, of mathematics itself [31,227]. It is imagined to consist of (1) a paper tape-infinite in both directions - that can be read, written on and be moved forwards and backwards by (2) the head, which can assume a finite number of states, including an initial state, and (3) a table, that - using as input only the current head state and the symbols on the tape directly under the headallows the head to write on the tape and move over it, in addition to changing its own state. Turing machines can be used to calculate many (but not all $[31,227,228]$ ) transcendental numbers such as $e$ and $\pi$.

Figure 20. The verge and anchor escapements. Escapements are applied in clocks. In the verge escapement the teeth of a rotating crown wheel periodically lift a pallet connected to the verge; the other pallet then impedes the movement of the teeth at the other end of the verge. In this way the sought-for periodic back-and-forth motion is induced. In the anchor escapement the anchor performs a back-and-forth motion as well, the difference being that here the rotation axis of the anchor is parallel to the axis of the escape wheel. Similar mechanisms may be operating in rotating biomolecular devices such as ATP Synthase and the flagellar motor, permitting them to function as clocks as well.

a. Verge escapement

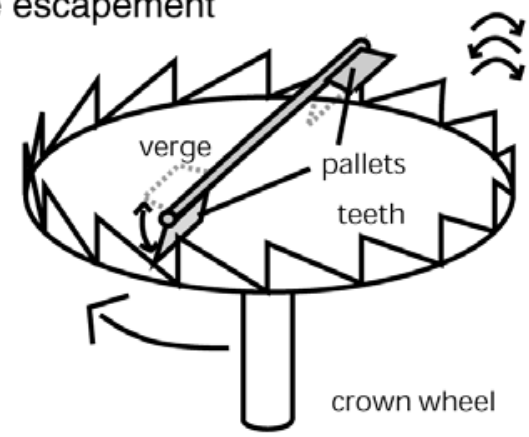

\section{b. Anchor escapement}

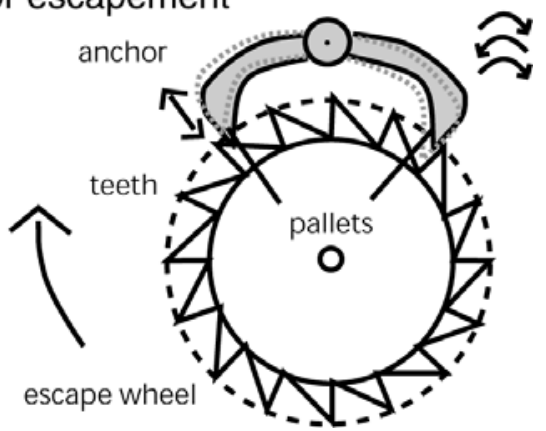

Turing proved that it is possible to obtain a description on paper tape of any Turing machine that can calculate a certain transcendental number, so that a special Turing machine, the 'Universal Turing Machine' (UTM), can calculate this transcendental number using this description on the tape. According to the Church-Turing thesis [229], theoretical computers based on different principles still have the same calculation ability as the UTM, which, because of this universality, constitutes a suitable reference. Physical devices based on the UTM have had a spectacular success in the nowadays ubiquitous electronic computer. 
Many physical implementations of Turing machines have been proposed, but many are also impractical because of low calculation speed. They may take many cycles to halt, which leads to the notion of a 'Turing tar-pit' [230]:

Beware of the Turing tar-pit in which everything is possible but nothing of interest is easy.

Halting is neither assured nor predictable $[31,228]$. Physical devices with computation capabilities different from the Turing machine may also be useful [231].

It follows from statistical mechanics that data storage of a bit such as on the paper tape and in the head of a physical implementation of a Turing machine cannot be $100 \%$ accurate [232]. More generally, errors are inherent to computer systems. According to Von Neumann [233]:

Error is viewed, therefore, not as an extraneous and misdirected or misdirecting accident, but as an essential part of the process under consideration-its importance in the synthesis of automata being fully comparable to that of the factor which is normally considered, the intended and correct logical structure.

Our present treatment of errors is unsatisfactory and ad hoc. It is the author's conviction, voiced over many years, that error should be treated by thermodynamic methods, and be the subject of thermodynamical theory, as information has been, by the work of L. Szilard and C.E. Shannon.

Whereas for the Turing machine it is assumed that errors during processing are absent - it is after all a logical, theoretical device - errors are significant in practical computers, and must especially have been significant in the first biological computers. Although Danchin [234] claims that the cell is a Turing machine, several differences between biological computation systems and Turing machines have been recognized [231]:

Turing computation, designed computation, is about halting, computability and universality; it is symbolic, discrete and closed (pre-defined); it is deterministic and sequential (in the sense that probabilistic or parallel variants provide no additional computation power); . . . its calculations are exceedingly fragile to small changes or errors. On the other hand, biological computation, found computation, is about not halting (halting equates system death); it is (mostly) nonsymbolic, continuous and open (constantly adapting and evolving due to the continual flow of matter, energy and information through the system); it is essentially stochastic and massively parallel; ... and is robust to many classes of errors.

We consider the Turing machine at least partly applicable over the whole size range of organisms, from microorganisms such as bacteria to macroscopic organisms like ourselves that have a brain. Key questions on biological computers then concern their specifics: How do they work, where are they located in the cell, how are programs physically realized, how did the machines evolve, what constitutes the difference between Turing and biological computation? Previous investigators have analysed the link between the flagellar computer and Turing machines only in general terms [235], and 
the extensive literature on the link between the Turing machine and the human brain that starts with Turing [31] himself gives little anatomical specifics.

Correspondences between the flagellar motor and the Turing machine exist of:

1. the ring of $26 \mathrm{Mot} \mathrm{A} / \mathrm{MotB}$ combinations in the flagellar motor can be linked to the paper tape; a similar number of switch complexes (FliG/FliM/FliN combinations) is present. The conformational state of a MotA/MotB combination or switch complex would stand for one bit. The motor is also able to read these conformational states while it turns: data can therefore be stored and read;

2. the switch complex can be linked to the Turing machine's head;

3. the head states to the current PMF, the conformations of the switch complex (CCW and CW), and the conformations of the flagellum - in addition to the $\mathrm{CCW}$ and $\mathrm{CW}$ state, additional changes in its shape are observed as well [204]. The state of tumbling is linked to the Turing machine's initial state;

4. the mechanical interaction between the proteins of the flagellar motor would implement the table.

It is consequently postulated that in a bacterium the functions of information processing, storage and action during chemotaxis are implemented by a flagellar computer of which the structure - but not the function - is identical to the flagellar motor. During a run, a single flagellar ratchet in a rotating bundle of flagellar motors functions as flagellar computer, with the rest of the rotating bundle forcing the ratchet/computer's rotation. The ratchet writes down in its set of MotA/MotB proteins the state of the environment during the run, as indicated by the absence of the CheY-P protein. When the number of set MotA/MotB proteins in the ratchet reaches the threshold, the system (1) resets these proteins (cf. the 'initial state' of a Turing machine), (2) tumbles, and (3) starts another run.

Chemotaxis demonstrates that alternatives in computing to the Turing machine are possible and that nature has discovered them. ${ }^{8}$ Proposed mechanisms for the flagellar computer could be confirmed by observation and experiment, in which conformational states of proteins are tracked by fluorescence or thermocoloration [236].

In addition to overcoming hardware and software errors, automated semi-periodic resetting overcomes the halting problem of the Turing machine. The name 'reset machine' is proposed for a computer with this reset capability. A regular reset should be seen not as a rough method-such as effected by a Windows user on a personal computer-for correcting hardware or software errors, but as a characteristic of a computer architecture that differs from the Turing machine. The reset machine accords with the recently formulated requirements for novel computing paradigms [237].

The model leaves open how the program is stored physically in the reset machine, and how it is reloaded. Moreover, a reset machine will function in a way different from a Turing machine, or even a regular computer: it is a distinct kind of automata. Upon a reset, data may have to be saved in stored memory. This may introduce errors in stored memory, and such damage may become significant in the long run, causing a kind of aging.

Webre et al. [194] attribute to a bacterium that performs chemotaxis a 'bacterial nanobrain' situated at the site of the membrane receptors, instead of in the flagellar motor. Additional types of signal transduction, and more complex phenomena, on longer timescales, have also been interpreted as indicating prokaryotic intelligence [238-240].

A related issue is the demonstrated presence in microorganisms of several types of memory different from regular DNA expression [241,242]. One could speak of computing when this memory is 
not simply the result of hysteresis of a non-linear reaction to environmental conditions, but can also be actively set by the organism. In a bacterium a network or maybe even a hierarchy of such, slightly coupled, data processing mechanisms may be present in addition to the bacterial flagellar computer.

\subsection{Emergence of the Eukaryotic Cell}

Until the nineties the large difference between the prokaryotic and the eukaryotic cell seemed conceptually insurmountable, but then many attributes considered typical of eukaryotes were also found in prokaryotes. Vellai and Vida [243] list the nucleus, cytoskeleton, mitosis-supporting apparatus, internal membrane, linear chromosome, introns, eukaryotic-gene regulation, multiple genomes and large size. Remaining attributes characteristic of eukaryotes are identified as (1) an energy-producing cell organelle, (2) endocytosis capability, and (3) an 100,000 times larger genome: whereas prokaryotes genomes typically contain 0.6-9.5 million bases, eukaryotic genomes start at 140,000 million bases. The large difference in the flagellar motors can be added [244,245] to these characteristics. The bacterial flagellar motor works on the PMF, whereas the larger eukaryotic flagellar motor works on ATP. The rotating bacterial flagellum may be present on its own, or be part of a bundle. The 'bundle' of $9+2$ microtubules inside the eukaryotic flagellum bends, a mechanism that may more easily scale up, as there seems to be a lower chance of entanglement of the longer microtubules. ${ }^{9}$

Figure 21. Proposed emergence of muscle from a thermotether inside a cell. Figure 2 depicts free energy gain from a thermotether outside a cell. A thermotether with an ATP generating FP attached to it operating inside a cell is also easily imagined. Reversal of such a system could lead to the emergence of muscle when an ATP-consuming FP evolved into myosin and the thermotether into actin.

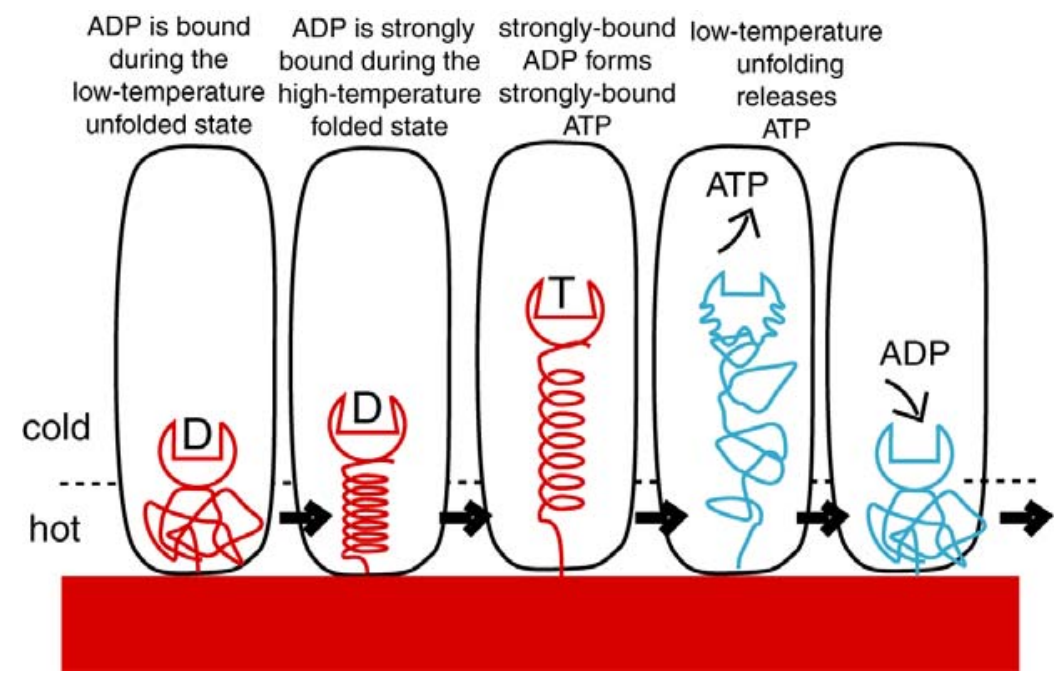

The emergence of muscle can be explained similar to the emergence of the bacterial flagellar motor. A global glaciation again yielded the long evolutionary time required for the emergence of a thermosynthesis driven process that started with a thermotether moving back-and-forth in the thermal gradient inside a cell (Figure 21). FPs attached to this internal thermotether generated condensation products such as ATP and GTP. Partial steps of the dissipative mechanisms of these proteins reversed 
at the end of the glaciation. The thermotether/FP combination would have turned into the actin/myosin couple of muscle. The source of the ATP required for muscle would have been respiration.

The bacterial flagellar motor runs on protons pumped by the respiratory chain, which is situated in the cytoplasmic membrane, the only membrane in the prokaryotic cell. In the bacterium, respiration generates the free energy for both the flagellar motor and for metabolism. The demands of these two systems may conflict. Their separation seems advantageous and feasible by endosymbiosis of the progenitor of the ATP-producing mitochondrion [248]. The ancient host of the mitochondrion, a subject of extensive debate in the biological literature [249,250], is thus identified as a flagellated bacterium.

By this endosymbiosis a division of labour was obtained that has remained present in organisms until today. The host transports substances to and from the mitochondria, which in turn generate the ATP with which the host runs this transport. A key aspect of the evolution of animals then concerns the evolution of transport. It would have started simple by a flagellar motor that ran on ATP, and would have ended with our own complex systems for circulation, locomotion, and food and oxygen uptake.

The mechanism of the prokaryotic flagellar ratchet proposed above is based on the rotating prokaryotic flagellum. The progenitor of the non- or less rotating eukaryotic flagellum may, in a thermal gradient, have generated ATP by a similar thermally induced bending: this progenitor would have constituted a eukaryotic flagellar ATP-generator that corresponded with the prokaryotic flagellar pump. Today's eukaryotic flagellum comprises several microtubule/dynein couples, and can be compared to a bundle of bacterial flagellar motors enclosed in a membrane (Figure 3f). The growth of microtubules by addition of the tubulin monomer resembles the growth of the bacterial flagellum by the addition of the FliC monomer to the flagellum's tip.

Emergence of an ATP-generating eukaryotic flagellar ratchet analogous to the proton-pumping bacterial flagellar ratchet seems feasible. Because of its bending it would resemble the invar-based circuit breaker used in car signalling lights mentioned in Section 2. The notion should be kept in mind when investigating choanoflagellates and the similar choanocytes present in sponges. Protist ciliates connected to a substrate show quick contractions of the tether/stalk even in the absence of a thermal gradient, which hints at the presence of a ratchet [174].

Another prospect for the theoretical eukaryotic flagellar ratchet is the observed flagellar cilium with its whip-like movement [251]. When present in a boundary layer it may span a thermal gradient. The flagellum's tip would have been thermally cycled during its movement, which therefore may have sustained a thermal relaxation oscillation. This mechanism may apply to the cilia in the bronchi of the lung where the temperature of inhaled air differs from the body temperature.

Movement driven by the temperature difference across the base of the cilium can also be imagined: by analogy to the reversed prokaryotic flagellar ratchet one derives the notion of the reversed eukaryotic flagellar ratchet, ${ }^{10}$ in which the high temperature of the cilium would drive the movement of the eukaryotic flagellum.

Eukaryotic complexity The task of resolving how the complex information processing and control occurring in the eukaryotic cell are physically implemented seems daunting. The unknown structure of a complex system may however be obtained by modelling its evolution: establish how it functioned in the beginning and then consider the later additions. Man-made complex systems such as 
airplanes - including their components such as jet engines - or computers (mainframe or personal) can be understood from their function. In contrast, it may be difficult to understand complex structures by the properties of their parts because of the redundancy in the numerous physicochemical properties that a part can have: the relevance of the properties of a part can only become clear from its function.

DNA [252,253], RNA [254] and proteins [255,256] can be used for in vitro non-biological computation. We consider an evolutionary path from a prokaryotic reset to a eukaryotic reset machine. If in addition to in vitro computation, in vivo computation by biological macromolecules could be demonstrated, the hardware involved would plausibly descend from the bacterial flagellar computer. The eukaryotic computer may then, also plausibly, be found near the flagellum, i.e. underneath the basal body of the eukaryotic cilium and near the pair of centrioles in the middle of the centrosome [257]. The cilium oscillates [258,259], and could therefore function as the clock of a computer. Recent studies indicate a central role in the control of the cell [260-262], including tumour suppression [263]. ${ }^{11}$ Jekely and Arendt [264] state:

The evolution of the motile cilium was a major innovation during eukaryogenesis that, in synergy with endomembranes, phagocytosis, mitochondria and novel genome organisation, triggered the rapid diversification of the eukaryotes.

The proposed descent of the eukaryotic cilium from the bacterial flagellar motor contrasts with the notion that it was a eukaryotic innovation [264]:

Both autogenous and symbiotic scenarios have been put forward to explain the evolutionary origin of the cilium. Autogenous scenarios propose that the cilium evolved by the duplication and divergence of pre-existing components of the eukaryotic cell whereas in symbiotic scenarios, the merger of a motile Spirochete and a host cell is thought to have given rise to the organelle.

Several physical models for the function of the microtubules in the cilium have been proposed. Some invoke classical conformational changes in tubulins [265-268], others invoke quantum processes including quantum computation [265-267]. Some models comprise temperature-dependent conformational transitions [268]. The structures used in these models may be easily linked to the prokaryotic and eukaryotic flagellar computers proposed here.

The animal brain, a biological computer based on the action potential of the cell membrane of the neuron, differs substantially from the flagellar computer. A following study [20] gives a model, based on the thermal diffusion potential [269], for the emergence of the nerve in a hydrothermal vent later in evolution at the onset of the Cambrian. Nerve-based computing would have been an add-on to an already functional eukaryotic flagellar computer that made use of the cilium.

Timing This study identifies macroevolution with global glaciations during which life would have fallen back to thermosynthesis. Tentatively, the $2.9 \mathrm{Ga}$ glaciation is associated with the emergence of the prokaryotic flagellar motor. Good dates for the first reported eukaryote fossils are $1.8 \mathrm{Ga}$ [141] and $2.1 \mathrm{Ga}[270]$ and their emergence is associated with the preceding global glaciation of 2.2 Ga. During the next global glaciations - the Snowball Earths of the late Proterozoic that start at $0.7 \mathrm{Ga}$ - larger versions of the thermotether and novel thermosynthesizing organs based on different relaxation 
oscillations would have emerged that supported movement of larger volumes of water. These novel organs will be the subject of following studies.

\section{Discussion}

We agree with Simon's statements [271]:

Biology's subject matter thus consists of a class of naturally occurring machines, machines that are assumed to be descended from primitive protomachines, the original progenitor of which was self-assembled.

and

Whether or not abiogenesis, the spontaneous and natural formation of living systems from inanimate materials alone, is explicable in terms of physical theory, it clearly cannot be explained in terms of biology.

Many notions used here indeed have their origin outside biology, in physics and engineering. While comparing machines to organisms, Simon further observed:

It is essential to almost all man-made machines that they introduce nonholonomic constraints, such as ratches, relays, switches and escapements.

This study demonstrates that ratchets also may have played a role during evolution, in the emergence of cell organelles, especially those involved in energy conversion and movement.

A key problem in biophysics is the question of how life during evolution overcame the overdamping of movement on the atomic scale $[151,153]$. The proposed solution, the thermotether, may have worked in the past in a thermal gradient, and may still be operating in thermal gradients in the world around us.

Additional support is given to the notion that during its origin and early evolution, life did not move actively but was carried along by convection currents. Later the thermal gradients near hydrothermal vents permitted the emergence of directed motion based on simple relaxation oscillations that overcame the damping due to a small size [20]. These processes gave thermosynthesizers a selective advantage during global glaciations and when these glacials ended, the reappearance of photosynthesis and respiration yielded the required energy for movement by mechanisms based on reversal of the previously acquired processes evolved from relaxation oscillations.

In contrast to the standard Darwinian scenario for evolution, which assumes small incremental changes, the newly proposed scenario permits large changes: a mechanism for macroevolution driven by glaciations is obtained [272-275]. Environmental fluctuations would have accelerated evolution [276,277]. Martin [278] has stated on the mechanism of the emergence of the eukaryotic nucleus that:

A fundamental problem that is common to all ideas regarding the origin of the nucleus is that the underlying mechanism has to be plausible enough to have actually occurred, but at the same 
time so unlikely that it has only occurred once in four billion years . . This problem is severe. . . . It is the main reason that they are all coupled to a rare event in evolution, for example the origin of phagotrophy, a karyogenic symbiosis that occurred only in the eukaryotic lineage, or the origin of mitochondria....

Such rare evolutionary events are therefore explained here by macroevolution driven by longlasting geological cycles of glacials and interglacials.

This study further increases the large explanatory power [279] of thermosynthesis. Seemingly disparate notions such as evolution, macroevolution, chemiosmosis, hydrothermal vents, global glaciations, heat engines, non-equilibrium thermodynamics, Feynman's ratchet-and-pawl mechanism, the bacterial flagellar motor and the eukaryotic cilium are combined in a unifying scenario that is verifiable by observation and experiment. The linkage of the flagellar motor to the Turing machine could have far-reaching consequences for the understanding of life: computation capability may be a key attribute of the so difficult to define living state [235]. Just as today's complex airplane can be understood as the result of the addition to a simple airplane of components that improve its function, the complexity of the eukaryotic cell may become understood as the result of the addition of specified components to a bacterial flagellar computer.

All theoretical modelling is easily called speculative, and this is in particular true for the modelling of the origin of life. The application of the notion of thermosynthesis to astrobiology [87] has been called 'science fiction' [280]. This author does not agree. Given the important role of heat engines in physics and engineering, and the absence of a reason that would preclude a similar role in biology, it follows that biological heat engines are possible and even plausible. They may not have been observed because biologists have not looked for them-most are unfamiliar with the possibility, and it is in general difficult for the eye to see what is not already in the mind. The absence of progress in solving the problem of the origin of life means that a fundamental idea has probably been overlooked, and there have been calls for 'open-mindedness' in this context [271]. The overlooked idea is not necessarily complex but may instead be simple. Biological heat engines functioning in a convection cell or in a thermal gradient are most suitable candidates for the overlooked fundamental idea that can explain the origin of life.

\section{Conclusions}

A simple theoretical cell organelle, the thermotether, is described that allows a microorganism to sustain a relaxation oscillation that generates free energy in the thermal gradient above a submarine hydrothermal vent. This thermotether may have played a key role during early evolution. A modified thermotether that worked on a $\mathrm{pH}$ gradient instead of on a thermal gradient is a plausible progenitor of the proton translocation subunits of ATP Synthase and the prokaryotic flagellar motor. The flagellar pump resembles Feynman's ratchet-and-pawl mechanism. A model can be given for the emergence of a Turing-like machine that plausibly functions in prokaryotic and eukaryotic cells. The notion of the thermotether further enhances the already large explanatory power of thermosynthesis in biology. 


\section{Acknowledgements}

Ronald Wouterson for a referral to the use of bimetal in car-signalling lights; Jaap Glas, Alice van der Laan and Amy E. Kelly for their suggestions for improving this and earlier versions of the manuscript.

\section{References}

1. Muller, A.W.J. Thermoelectric energy conversion could be an energy source of living organisms. Phys. Lett. A 1983, 96, 319-321.

2. Muller, A.W.J. Thermosynthesis by biomembranes: energy gain from cyclic temperature changes. J. Theor. Biol. 1985, 115, 429-453.

3. Muller, A.W.J. A mechanism for thermosynthesis based on a thermotropic phase transition in an asymmetric biomembrane. Physiol. Chem. Phys. Med. NMR 1993, 25, 95-111.

4. Muller, A.W.J. Were the first organisms heat engines? A new model for biogenesis and the early evolution of biological energy conversion. Prog. Biophys. Mol. Biol. 1995, 63, 193-231.

5. Muller, A.W.J. Thermosynthesis as energy source for the RNA world: A model for the bioenergetics of the origin of life. BioSystems 2005, 82, 93-102.

6. Muller, A.W.J. Photosystem 0, a proposed ancestral photosystem without reducing power that that synthesized ATP during light-dark cycling; Available online at http: //www.arXiv.net/physics/0501050 (accessed September 16, 2009).

7. Muller, A.W.J.; Schulze-Makuch, D. Sorption heat engines: simple inanimate negative entropy generators. Physica A 2006, 362, 369-381.

8. Muller, A.W.J.; Schulze-Makuch, D. Thermal energy and the origin of life. Orig. Life Evol. Biosph. 2006, 36, 177-189.

9. Conway Morris, S. Darwin's dilemma: the realities of the Cambrian explosion. Proc. Trans. $R$. Soc. B 2006, 361, 1069-1083.

10. Darwin, C. On the Origin of Species by means of Natural Selection; J. Murray: London, UK, 1859.

11. Glaessner, M.F. The Dawn of Animal Life: a Biohistorical Study; Cambridge University Press: Cambridge, UK, 1984.

12. McCall, G.J.H. The Vendian (Ediacaran) in the geological record: enigmas in geology's prelude to the Cambrian explosion. Earth-Sci. Rev. 2006, 77, 1-229.

13. Narbonne, G.M. The Ediacara biota: a terminal Neoproterozoic experiment in the evolution of life. GSA Today 1998, 8, 1-6.

14. Chen, J.-W.; Oliveri, P.; Gao, F.; Dornbos, S.Q.; Li, C.-W.; Bottjer, D.J.; Davidson, E.H. Precambrian animal life: probable developmental and adult cnidarian forms from Southwest China. Dev. Biol. 2002, 248, 182-196.

15. Narbonne, G.M. Modular construction of early Ediacaran complex life forms. Science 2004, 305, 1141-1144.

16. Xiao, S.; Shen, B.; Zhou, C.; Xie, G.; Yuan, X. A uniquely preserved Ediacaran fossil with direct evidence for a quilted bodyplan. Proc. Nat. Acad. Sci. USA 2005, 102, 10227-10232. 
17. Hoffman, P.J.; Kaufman, A.J.; Halverson, G.P.; Schrag, D.P. A neoproterozoic snowball Earth. Science 1998, 281, 1342-1346.

18. Kirschvink, J.L. Late Proterozoic, low-latitude global glaciation, The Snowball Earth. In The Proterozoic Biosphere: A Multidisciplinary Study; Schopf, J.W., Klein, C., Eds.; Cambridge University Press: Cambridge, UK, 1992; pp. 51-52.

19. Mawson, D. The late Precambrian ice-age and glacial record of the Bibliando dome. J. Proc. Roy. Soc. New South Wales 1949, 82, 150-174.

20. Muller, A.W.J. Animal emergence during Snowball Earths by thermosynthesis in submarine hydrothermal vents; Available online at http://precedings.nature.com/documents/3333/version/2 (accessed September 16, 2009).

21. Muller, A.W.J. Emergence of animals during Snowball Earths from biological heat engines in the thermal gradient above submarine hydrothermal vents. Orig. Life Evol. Biosph. 2009, 39, 320-321.

22. Rasmussen, B. Filamentous microfossils in a 3,235-million-year-old volcanogenic massive sulphide deposit. Nature 2000, 405, 676-679.

23. van der Pol, B.; van der Mark, J. The heartbeat considered as a relaxation oscillation, and an electrical model of the heart. Philos. Mag. Suppl. 1928, 6, 763-775.

24. Brandts, J.F. Heat effects on proteins and enzymes. In Thermobiology; Rose, A.H., Ed.; Academic Press: London, UK, 1967; pp. 25-72.

25. Todgham, A.E.; Hoaglund, E.A.; Hoffman, G.E. Is cold the new hot? Elevated ubiquitinconjugated protein levels in tissues of Antarctic fish as evidence for cold-denaturation of proteins in vivo. J. Comp. Physiol. B 2007, 177, 857-866.

26. Hueck, C.J. Type III protein secretion systems in bacterial pathogens of animals and plants. Microb. Mol. Biol. Rev. 1998, 62, 379-433.

27. Feynman, R.; Leighton, R.; Sands, M. The Feynman Lectures on Physics; Addison-Wesley: Reading, MA, USA, 1963.

28. Machura, L. Performance of Brownian Motors; Ph.D. Thesis, University of Augsburg: Augsburg, Germany, 2006.

29. von Smoluchowski, M. Experimentell nachweisbare, der üblichen Thermodynamik widersprechende Molekularphänome. Physik. Zeitschr. 1912, 13, 1069-1080.

30. Berg, H.C. The rotary motor of bacterial flagella. Annu. Rev. Biochem. 2003, 72, 19-54.

31. Turing, A. On computable numbers, with an application to the Entscheidungsproblem. Proc. London Math. Soc. 2 1937, 42, 230-265.

32. Cramer, W.A.; Knaff, D.B. Energy Transduction in Biological Membranes. A Textbook of Bioenergetics; Springer-Verlag: New York, NY, USA; 1991.

33. Dimroth, P.; Von Ballmoos, C.; Meier, T. Catalytic and mechanical cycles in F1-ATP synthases. EMBO Rep. 2006, 7, 276-282.

34. Mitchell, P. Coupling of phosphorylation to electron and proton transfer by a chemi-osmotic type of physiology. Nature 1961, 191, 144-148.

35. Mitchell, P. Keilin's respiratory chain concept and its chemiosmotic consequences. Science 1979, 206, 1148-1159.

36. Williams, R.J.P. Possible functions of chains of catalysts. J. Theor. Biol. 1961, 1, 1-17. 
37. Harold, F.M. Gleanings of a chemiosmotic eye. BioEssays 2001, 23, 848-855.

38. Carnot, S. Réflexions sur la puissance motrice du feu et sur les machines propres a développer cette puissance; Bachelier: Paris, France, 1824.

39. Gonzalo, J.A. Ferroelectric materials as energy converters. Ferroelectrics 1976, 11, 423-430.

40. Hoh, S.R. Energy converter. U.S. Patent 3073974, 1963.

41. Pulvari, C.F.; Garcia, F.J. Conversion of solar to electrical energy utilizing the thermodielectric effect. Ferroelectrics 1978, 22, 769-771.

42. Sklar, A.A. A Numerical Investigation of a Thermodielectric Power Generation System; Ph.D. Thesis, Georgia Institute of Technology: Atlanta, GE, USA, 2005.

43. Tesla, N. Thermo magnetic motor. U.S. Patent 396121, 1889.

44. Wekjira, J.F. The VT1 Shape Memory Alloy Heat Engine Design; Ph.D. Thesis Virginia Polytechnic Institute: Blacksburg, VA, USA, 2001.

45. Wiegand, W.B.; Snyder, J.W. The rubber pendulum, the Joule effect, and the dynamic stress strain curve. Inst. Rubber Ind. Trans. Proc. 1934, 10, 234-262.

46. Mullen, J.G.; Look, G.W.; Konkel, J. Thermodynamics of a simple rubber-band heat engine. Am. J. Phys. 1975, 43, 349-353.

47. Savarino, G.; Fisch, M.R. A general physics laboratory investigation of the thermodynamics of a rubber band. Am. J. Phys. 1991, 59, 141-145.

48. Singh, R. A rubber heat engine for ground water irrigation in India. Agric. Ecosyst. Environ. 1989, 25, 271-278.

49. Flory, P.J. Principles of Polymer Chemistry; Cornell University Press: Ithaca, NY, USA, 1953.

50. Flory, P.J. Theory of elastic mechanisms in fibrous proteins. J. Am. Chem. Soc. 1956, 78, 5222-5235.

51. Wöhlisch, E. Muskelphysiologie vom Standpunkt der kinetische Theorie der Hochelastizität und der Entspannungshypothese des Kontraktionsmechanismus. Naturwissenschaften 1940, 28, 305-312.

52. Reed, R.C. The Superalloys. Fundamentals and Applications; Cambridge University Press: Cambridge, UK, 2006.

53. Hollerbach, R. On the theory of the geodynamo. Phys. Earth Planet. Interiors 1996, 98, $163-$ 185.

54. Roberts, P.H.; Soward, A.M. Dynamo theory. Annu. Rev. Fluid Mech. 1992, 24, 459-512.

55. Zhang, K.; Schubert, G. Magnetohydrodynamics in rapidly rotating spherical shells. Annu. Rev. Fluid Mech. 2000, 32, 411-445.

56. Schubert, G.; Turcotte, D.L.; Olson, P. Mantle Convection in the Earth and Planets; Cambridge University Press: Cambridge, UK, 2001.

57. Warren, B.A. Deep circulation of the world ocean. In Evolution of Physical Oceanography. Scientific Surveys in Honor of Henry Stommel; Warren, B.A., Ed.; MIT Press: Cambridge, MA, USA, 1981; pp. 6-41.

58. Wunsch, C.; Ferrari, R. Vertical mixing, energy, and the general circulation of the oceans. Annu. Rev. Fluid Mech. 2004, 36, 281-314.

59. Broda, E. The Evolution of the Bioenergetic Processes; Pergamon: Oxford, UK, 1975. 
60. Florkin, M. A history of biochemistry. In Comprehensive Biochemistry; Florkin, M., Stotz, E.H., Eds.; Elsevier: Amsterdam, Netherlands, 1972; Vol. 30, p. 244.

61. Komissarov, G.G. Photosynthesis as a thermal process. In Current Research in Photosynthesis; Baltscheffsky, M., Ed.; Kluwer: Deventer, 1990; Vol. 4, pp. 107-110.

62. Van Holde, K.E. The origins of life: a thermodynamic critique. In The Origins of Life and Evolution; Halverson, H.O., Van Holde, K.E., Eds.; Alan Liss: New York, 1980; pp. 31-46.

63. Engelmann, T.W. Über den Ursprung der Muskelkraft; Juvenile Nonfiction: Leipzig, Germany, 1893.

64. Fick, A. Einige Bemerkungen zu Engelmann's Abhandlung über den Ursprung der Muskelkraft. Arch. Ges. Physiol. 1893, 53, 606-615.

65. Fick, A. Noch einige Bemerkungen zu Engelmann's Schrift über den Ursprung der Muskelkraft. Arch. Ges. Physiol. 1893, 54, 313-318.

66. Guillaume, C.E. Recherche sur les aciers au nickel. Dilatations aux temperature elevees; resistance electrique. Comptes Rendus Acad. Sci. 1897, 125, 235-238.

67. Shock, E.L. Geochemical constraints of the origin of organic compounds in hydrothermal systems. Orig. Life. Evol. Biosph. 1990, 20, 331-367.

68. Rosing, J.; Slater, E.C. The value of $\Delta \mathrm{G}^{0}$ for the hydrolysis of ATP. Biochim. Biophys. Acta 1972, 267, 275-290.

69. Giersch, C.; Heber, U.; Kobayashi, Y.; Inoue, Y.; Shibata, K.; Heldt, H.W. Energy charge, phosphorylation potential and proton motive force in chloroplasts. Biochim. Biophys. Acta 1980, 590, 59-73.

70. Schlodder, E.; Gräber, P.; Witt, H.T. Mechanism of phosphorylation in chloroplasts. Top. Photosynth. 1982, 4, 105-175.

71. Hardt, S.L. A measurable consequence of the Mitchell theory of phosphorylation. J. Theor. Biol. 1980, 87, 1-7.

72. Kettner, C.; Bertl, A.; Obermyer, G.; Slayman, C.; Bihler, H. Electrophysiological analysis of the yeast $\mathrm{V}$-type proton pump, variable coupling ratio and proton shunt. Biophys. J. 2003, 85, 3730-3738.

73. Toei, M.; Gerle, C.; Nakano, M.; Tani, K.; Gyobu, N.; Tamakoshi, M.; Sone, N.; Yoshida, M.; Fujiyoshi, Y.; Mitsuoka, K.; Yokoyama, K. Dodecamer rotor ring defines $\mathrm{H}^{+} / \mathrm{ATP}$ ratio for ATP synthesis of prokaryotic V-ATPase from Thermus thermophilus. Proc. Nat. Acad. Sci. USA 2007, 104, 20256-20261.

74. Tomasek, J.J.; Brusilow, W.S.A. Stoichiometry of energy coupling by proton-translocating ATPases: a history of variability. J. Bioenerg. Biomemb. 2000, 32, 493-500.

75. Steigmiller, S.; Turina, P.; Gräber, P. The thermodynamic $\mathrm{H}^{+} / \mathrm{ATP}$ ratios of the $\mathrm{H}^{+}$-ATP synthases from chloroplasts and Escherichia coli. Proc. Nat. Acad. Sci. USA 2008, 105, 37453750.

76. Gafni, A.; Boyer, P.D. Modulation of stochiometry of the sarcoplasmic reticulum calcium pump may enhance thermodynamic efficiency. Proc. Nat. Acad. Sci. USA 1985, 82, 98-101.

77. Konings, W.N.; Booth, I.R. Do the stoichiometries of ion-linked transport systems vary? Trends Biochem. Sci. 1981, 6, 257-262. 
78. Feniouk, B.A.; Mulkidjanian, A.Y.; Junge, W. Proton slip in the ATP synthase of Rhodobacter capsulatus: induction, proton conduction, and nucleotide dependence. Biochim. Biophys. Acta 2005, 1706, 184-194.

79. Azzone, G.F.; Pozzan, T.; Massari, S.; Bragadin, M. Proton electrochemical gradient and rate of controlled respiration in mitochondria. Biochim. Biophys. Acta 1978, 501, 296-306.

80. Azzone, G.F.; Pozzan, T.; Massari, S. Proton electrochemical gradient and phosphate potential in mitochondria. Biochim. Biophys. Acta 1978, 501, 307-316.

81. Azzone, G.F.; Pozzan, T.; Massari, S. Proton electrochemical gradient and phosphate potential in submitochondria particles. Biochim. Biophys. Acta 1978, 501, 317-329.

82. Boyer, P.D. The ATP synthase - a splendid molecular machine. Annu. Rev. Biochem. 1997, 66, 717-749.

83. Boyer, P.D. The binding change mechanism of ATP synthesis. In Membrane Bioenergetics; Lee, C.P., Schatz, G., Enster, L., Eds.; Addison-Wesley: London, UK, 1979; pp. 461-479.

84. DeMeis, L. Role of water in energy of hydrolysis of phosphate compounds-energy transduction in biological membranes. Biochim. Biophys. Acta 1989, 973, 333-349.

85. Muller, A.W.J. The thermosynthesis model for the origin of life and the emergence of regulation by $\mathrm{Ca}^{2+}$. Essays Biochem. 1996, 31, 103-119.

86. Muller, A.W.J. Finding extraterrestrial organisms living on thermosynthesis. Astrobiology 2003, 3, 555-564.

87. Black, S. Pre-cell evolution and the origin of enzymes. Nature 1970, 226, 754-755.

88. Copley, S.D. Enzymes with extra talents; moonlighting functions and catalytic promiscuity. Curr. Opin. Chem. Biol. 2003, 7, 265-272.

89. Kazlauskas, R.J. Enhancing catalytic promiscuity for biocatalysis. Curr. Opin. Chem. Biol. 2005, 9, 195-201.

90. Khersonsky, O.; Roodveldt, C.; Tawfik, D.S. Enzyme promiscuity: evolutionary and mechanistic aspects. Curr. Opinion Chem. Biology 2006, 10, 498-508.

91. Hult, K.; Berglund, P. Enzyme promiscuity: mechanism and applications. Trends Biotechnol. 2007, 25, 231-238.

92. Jao, S.C.; Huang, L.F.; Tao, Y.S.; Li, W.S. Hydrolysis of organophosphate triesters by Escherichia coli aminopeptidase P. J. Mol. Catal. B-Enzym. 2004, 27, 7-12.

93. Villaverde, J.; Cladera, J.; Hartog, A.; Berden, J.; Padros, E.; Dunach, M. Nucleotide and $\mathrm{Mg}^{2+}$ dependency of the thermal denaturation of mitochondrial $\mathrm{F}_{1}$-ATPase. Biophys. J. 1998, 75, 1980-1988.

94. Wang, Z.Y.; Freire, E.; McCarthy, R.E. Influence of nucleotide binding site occupancy on the thermal stability of the $\mathrm{F}_{1}$ portion of the chloroplast ATP Synthase. J. Biol. Chem. 1993, 268, 20785-20790.

95. Hightower, K.E.; McCarty, R.E. Influence of nucleotides on the cold stability of chloroplast coupling factor 1. Biochemistry 1996, 35, 10051-10057.

96. Vinogradov, A.D. Mitochondrial ATP Synthase: fifteen years later. Biochemistry (Moscow) 1999, 64, 1219-1229.

97. Sun, F.-J.; Caetano-Anolles, G. The origin and evolution of tRNA inferred from phylogenetic analysis of structure. J. Mol. Evol. 2008, 66, 21-35. 
98. Cuezva, J.M.; Sánchez-Aragó, M.; Sala, S.; Blanco-Rivero, A.; Ortega, A.D. A message emerging from development: the repression of mitochondrial $\beta$-F1-ATPase expression in cancer. J. Bioenerg. Bioembr. 2007, 39, 259-265.

99. Corliss, S.B.; Dymond, J.; Gordon, L.I.; Edmond, J.M.; von Herzen, R.P.; Ballard, R.D.; Green, K.; Williams, D.; Bainbridge, A.; Crane, K.; van Andel, T.H. Submarine thermal springs on the Galápagos Rift. Science 1979, 203, 1073-1083.

100. Baross, J.A.; Hoffman, S.E. Submarine hydrothermal vents and associated gradient environments as sites for the origin and evolution of life. Orig. Life 1985, 15, 327-345.

101. Corliss, S.B.; Baross, J.A.; Hoffman, S.E. An hypothesis concerning the relationship between submarine hot springs and the origin of life on Earth. Oceanologica Acta 1981, 4 (suppl), 59-69.

102. Reed, C. Boiling points. Nature 2006, 439, 905-907.

103. Bisschoff, J.L.; Rosenbauer, R.J. The critical point of and two-phase boundary of seawater. 200-500 ${ }^{\circ}$ C. Earth Planet. Sc. Lett. 1984, 68, 172-180.

104. Bisschoff, J.L.; Rosenbauer, R.J. Liquid-vapor relations in the critical region of the system $\mathrm{NaCl}-\mathrm{H}_{2} \mathrm{O}$ from 380 to $415{ }^{\circ} \mathrm{C}$ : A refined determination of the critical point and the two-phase boundary of seawater. Geochim. Cosmochim. Acta 1988, 52, 2121-2126.

105. Miller, S.L.; Bada, J.L. Submarine hot springs and the origin of life. Nature 1988, 334, 609-611.

106. Kelley, D.S.; Karson, J.A.; Blackman, D.K.; Früh-green, G.L.; Butterfield, D.A.; Lilley, M.D.; Olson, E.J.; Schrenk, M.O.; Roe, K.K.; Lebon, G.T.; Rivizzigno, P. The AT3-60 ship board party. An off-axis hydrothermal vent field near the Mid-Atlantic Ridge at $30^{\circ} \mathrm{N}$. Nature 2001, 412, 145-149.

107. Pirajno, F.; van Kranendonk, M.J. Review of hydrothermal processes and systems on Earth and implications for Martian analogues. Aust. J. Earth Sci. 2005, 52, 329-351.

108. Bada, J.L.; Lazcano, A. Origin of life, some like it hot—but not the first biomolecules. Science 2002, 296, 1982-1983.

109. Woese, C. Bacterial evolution. Microbiol. Rev. 1987, 51, 221-271.

110. Miller, S.L.; Lazcano, A. The origin of life_did it occur at high temperatures? J. Mol. Evol. 1995, 41, 689-692.

111. Martin, W.; Russell, M.J. On the origins of cells: a hypothesis for the evolutionary transitions from abiotic geochemistry to chemoautotrophic prokaryotes, and from prokaryotes to nucleated cells. Phil. Trans. Roy. Soc. Lond. B 2002, 385, 59-85.

112. Russell, M.J.; Arndt, N.T. Geodynamic and metabolic cycles in the Hadean. Biogeosciences 2005, 2, 97-111.

113. Russell, M.J.; Hall, A.J. The emergence of life from iron monosulphide bubbles at a submarine hydrothermal redox and pH front. J. Geol. Soc. Lond. 1997, 154, 377-402.

114. Vlassov, A.V.; Kazakov, S.A.; Johnston, B.H.; Landweber, L.F. The RNA World on ice: a new scenario for the emergence of RNA information. J. Mol. Evol. 2005, 61, 264-273.

115. Bahn, P.R.; Pappelis, A.; Grubbs, R. The role of heat in the origin of life. In Life in the Universe; Seckbach, J., Ed.; Kluwer: Dordrecht, The Netherlands, 2004; pp. 119-120.

116. Fox, S.W.; Dose, K. Molecular Evolution and the Origin of Life; Marcel Dekker: New York, NY, USA, 1977. 
117. Buford Price, P. Microbial life in glacial ice and implications for a cold origin of life. FEMS Microbiol. Ecol. 2007, 59, 213-231.

118. Trinks, H.; Schroeder, W.; Biebricher, C.K. Ice and the origin of life. Orig. Life Evol. Biosph. 2005, 35, 429-445.

119. Halliday, A.N. Terrestrial accretion rates and the formation of the Moon. Earth Plan. Science Lett. 2000, 176, 17-30.

120. Chyba, C.F. The violent environment of the origin of life: progress and uncertainties. Geochim. Cosmochim. Acta 1993, 57, 3351-3358.

121. Cohen, B.A.; Swindle, T.D.; King, D.A. Support for the lunar cataclysm hypothesis from lunar meteorite impact melt ages. Science 2000, 290, 1754-1756.

122. Ryder, G. Lunar samples, lunar accretion and the end of the early bombardment of the Moon. Eos 1990, 71, 322-323.

123. Sleep, N.H.; Zahnle, K.J.; Kasting, J.F.; Morowitz, H.J. Annihilation of ecosystems by large asteroid impacts on the early Earth. Nature 1989, 342, 139-142.

124. Horneck, G.; Stöffler, D.; Ott, S.; Hornemann, U.; Cockell, C.S.; Moeller, R.; Meyer, C.; De Vera, J.-P.; Fritz, J.; Schade, S.; Artemieva, A. Microbial inhabitants survive hypervelocity impacts on Mars-like host planets: first phase of lithopanspermia experimentally tested. Astrobiology 2008, 8, 17-43.

125. Stöffler, D.; Horneck, G.; Ott, S.; Hornemann, U.; Cockell, C.S.; Moeller, R.; Meyer, C.; De Vera, J.-P.; Fritz, J.; Artemieva, A. Experimental evidence for the potential impact ejection of viable microorganisms from Mars and Mars-like planets. Astrobiology 2008, 8, 585-588.

126. Khalil, M.A.K. Non- $\mathrm{CO}_{2}$ greenhouse gases in the atmosphere. Annu. Rev. Energ. Environ. 1999, 24, 645-661.

127. Tajika, E. Faint young Sun and the carbon cycle: implications for the Proterozoic global glaciations. Earth Planet. Sci. Lett. 2003, 214, 443-453.

128. Gough, D.O. Solar interior structure and luminosity variations. Sol. Phys. 1981, 74, 21-34.

129. Bada, J.L.; Bigham, C.; Miller, S.L. Impact melting of frozen oceans on the early Earth: implications for the origin of life. Proc. Nat. Acad. Sci. USA 1994, 91, 1248-1250.

130. Sagan, C.; Mullen, G. Earth and Mars: evolution of atmospheres and surface temperatures. Science 1972, 177, 52-56.

131. Valley, J.W.; Peck, W.H.; King, E.M.; Wilde, S.A. A cool early Earth. Geology 2002, 30, 351-354.

132. Kharecha, P.; Kasting, J.F.; Siefert J.L. A coupled atmosphere-ecosystem model of the Early Archean Earth. Geobiology 2005, 3, 53-76.

133. Thauer, R.K. Biochemistry of methanogenesis: a tribute to Marjorie Stephenson. Microbiology 1998, 144, 2377-2406.

134. Kasting, J.F.; Howard, M.T. Atmospheric composition and climate on the early Earth. Phil. Trans. R. Soc. B 2006, 361, 1733-1742.

135. Kasting, J.F.; Ono, S. Palaeoclimates: the first two billion years. Phil. Trans. R. Soc. B 2006, $361,917-929$. 
136. Young, G.M.; von Brunn, V.; Gold, D.J.C.; Minter, W.E.L. Earth's oldest reported glaciation; physical and chemical evidence from the Archean Mozaan Group ( 2.9 Ga) of South Africa. $J$. Geol. 1998, 106, 523-538.

137. Evans, D.A.; Beukes, N.J.; Kirschvink, J.L. Low-latitude glaciation in the Palaeoproterozoic era. Nature 1997, 386, 262-266.

138. Kasting, J.F.; Eggler, D.H.; Raeburn, S.P. Mantle redox evolution and the oxidation state of the Archean atmosphere. J. Geol. 1993, 101, 245-257.

139. Schwartzman, D.; Caldeira, K.; Pavlov, A. Cyanobacterial emergence at 2.8 Gya and greenhouse feedbacks. Astrobiology 2008, 8, 187-203.

140. Bekker, A.; Holland, H.D.; Wang, P.-L.; Rumble, D.; Stein, H.J.; Hannah, J.L.; Coetzee, L.L.; Beukes, N.J. Dating the rise of atmospheric oxygen. Nature 2004, 427, 117-120.

141. Knoll, A.H.; Javaux, E.J.; Hewitt, D.; Cohen, P. Eukaryotic organisms in Proterozoic oceans. Phil. Trans. R. Soc. B 2006, 361, 1023-1038.

142. Huston, D.L.; Logan, G.A. Barite, BIFs and bugs, evidence for the evolution of the Earth's early atmosphere. Earth Planet. Sci. Lett. 2004, 220, 41-55.

143. Slack, J.F.; Grenne, T.; Bekker, A.; Rouxel, O.J.; Lindberg, P.A. Suboxic deep seawater in the late Paleoproterozoic: evidence from hematitic chert and iron formation related to seafloorhydrothermal sulfide deposits, central Arizona, USA. Earth Planet. Sci. Lett. 2007, 255, 243-256.

144. Armstrong, J.C.; Wells, L.E.; Gonzales, G. Rummaging through Earth's attic for remains of ancient life. Icarus 2002, 160, 183-196.

145. Vekshin, N.L. Thermal-model of coupling ATP synthesis with electron-transfer. Biofizika 1991, 36, 994-999.

146. Matsuno, K. Physics underlying the formation of protocells. J. Biol. Phys. 1995, 20, 117-121.

147, Matsuno, K. A possible prebiotic heat engine. Orig. Life Evol. Biosph. 1996, 26, 458.

148. Imai, E.; Honda, H.; Brack, A.; Matsuno, K. Elongation of oligopeptides in a simulated submarine hydrothermal system. Science 2005, 283, 831-833.

149. Kompanichenko, V.; Frisman, E.; Fishman, B.; Savenkova, E.; Shlufman, K. Exploration of thermodynamic fluctuations in the probable hydrothermal medium for the origin of life (on the example of Mutnovsky hydrothermal system in Kamchatka). Int. J. Astrobiology 2008, 6, 74.

150. Purcell, E.M. Life at low Reynolds number. Am. J. Phys. 1977, 45, 3-11.

151. Richardson, S.M. Fluid Mechanics; Hemisphere Publishing: New York, NY, USA, 1989; p. 202.

152. Howard, J. Mechanics of Motor Proteins and the Cytoskeleton; Sinauer: Sunderland, MA, USA, 2001.

153. Friedel, M.; Baumketner, A.; Shea, J.-E. Effects of surface tethering on protein folding mechanisms. Proc. Natl Acad. Sci. USA 2006, 103, 8396-8401.

154. Kramer, H.A. Brownian motion in a field of force and the diffusion model of chemical reactions. Physica 1940, 7, 284-304.

155. Frauenfelder, H.; Fenimore, P.W.; Chen, G.; McMahon, B.H. Protein folding is slaved to solvent motions. Proc. Nat. Acad. Sci. USA 2006, 103, 15469-15472. 
156. Doebeli, M.; Dieckmann, U. Speciation along environmental gradients. Nature 2003, 421, 259-264.

157. White, S.H.; VonHeijne, G. How translocons select transmembrane helices. Annu. Rev. Biophys. 2008, 37, 23-42.

158. Cornelis, G.R. The type III secretion injectisome. Nat. Rev. Microbiol. 2006, 4, 811-825.

159. Galan, J.E.; Wolf-Watz, H. Protein delivery into eukaryotic cells by type III secretion machineries. Nature 2006, 444, 567-573.

160. Holland, I.B. Translocation of bacterial proteins - an overview. Biochim. Biophys. Acta 2004, 1694, 5-16.

161. MacNab, R.M. Type III flagellar protein export and flagellar assembly. Biochim. Biophys. Acta 2004, 1694, 207-217.

162. Wickner, W.; Schekman, R. Protein translocation across biological membranes. Science 2005, 310, 1452-1456.

163. Steinberg, I.Z.; Oplatka, A.; Katchalsky, A. Mechanochemical engines. Nature 1966, 210, 568-571.

164. Hofmann, B.A.; Farmer, J.D.; Von Blanckenburg, F.; Fallick, A.E. Subsurface filamentous fabrics: an evaluation of origins based on morphological and geochemical criteria, with implications for exopaleontology. Astrobiology 2008, 8, 87-117.

165. Reysenbach, A.-L.; Cady, S.L. Microbiology of ancient and modern hydrothermal systems. Trends Microbiol. 2001, 9, 79-86.

166. Schopf, J.W. Fossil evidence of Archaean life. Phil. Trans. R. Soc. B 2006, 361, 869-885.

167. Santelli, C.M.; Orcutt, B.N.; Banning, E.; Bach, W.; Moyer, C.L.; Sogin, M.L.; Staudigel, H.; Edwards, K.J. Abundance and diversity of microbial life in ocean crust. Nature 2008, 453, 653-657.

168. Levin, L.A. Deep-ocean life where oxygen is scarce. Am. Scientist 2002, 90, 436-444.

169. Horita, J. Some perspectives on isotope biosignatures for early life. Chem. Geol. 2005, 218, 171-186.

170. Schulz, H.N.; Jørgensen, B.B. Big bacteria. Annu. Rev. Microbiol. 2001, 55, 105-107.

171. Jannasch, H.W.; Wirsen, C.O. Morphological survey of microbial mats near deep-sea thermal vents. Appl. Environm. Microbiol. 1981, 41, 528-538.

172. Kalanetra, K.M.; Huston, S.L.; Nelson, D.C. Novel, attached, sulphur-oxidizing bacteria at shallow hydrothermal vents possess vacuoles not involved in respiratory nitrate accumulation, Appl. Environm. Microbiol. 2004, 70, 7487-7496.

173. Nelson, D.C.; Wirson, C.O.; Jannasch, H.W. Characterization of large, autotrophic Beggiatoa spp. abundant at hydrothermal vents of the Guaymas Basin. Appl. Environm. Microbiol. 1989, 55, 2909-2917.

174. Moriyama, Y.; Hiyama, A.; Asai, H. High-speed video cinematographic demonstration of stalk and zooid contraction of Vorticella convallaria. Biophys. J. 1998, 74, 487-491.

175. De Groot, S.R.; Mazur, P. Non-equilibrium Thermodynamics; North-Holland Publishing: Amsterdam, The Netherlands, 1962.

176. Haase, R. Thermodynamik der irreversiblen Prozesse; Dietrich Steinkopf: Darmstadt, Germany, 1963. 
177. Baker, J.E. Free energy transduction in a chemical motor model. J. Theor. Biol. 2004, 228, 467-471.

178. Andersen, O.S.; Koeppe, R.E. Bilayer thickness and protein function: an energetic perspective. Annu. Rev. Biophys. Mol. Struct. 2007, 36, 107-130.

179. Russell, M.J. The alkaline solution to the emergence of life: energy, entropy and early evolution. Acta Biotheor. 2007, 55, 133-179.

180. Jagendorf, A.T.; Uribe, E. ATP formation caused by acid-base transition of spinach chloroplasts. Proc. Nat. Acad. Sci. USA 1966, 55, 170-177.

181. Simpson, E.D.; Finney, W.H. The effect of acids and their salts on heat contraction of rat tendon. Q. J. Exp. Physiol. 1930, 20, 115-123.

182. Angevine, C.M.; Herold, K.A.G.; Fillingame, R.H. Aqueous access pathways in subunit $a$ of rotary ATP synthase extend to both sides of the membrane. Proc. Nat. Acad. Sci. USA 2003, 100, 13179-13183.

183. Steed, P.R.; Fillingame, R.H. Subunit $a$ facilitates aqueous access to a membrane-embedded region of subunit $c$ in Escherichia coli $\mathrm{F}_{1} \mathrm{~F}_{\mathrm{o}}$ ATP Synthase. J. Biol. Chem. 2008, 283, 12365-12372.

184. Vincent, O.D.; Schwem, B.E.; Steed, P.R.; Fillingame, R.H. Fluidity of structure and swiveling of helices in the subunit $c$ ring of Escherichia coli ATP Synthase as revealed by cysteinecysteine cross linking. J. Biol. Chem. 2007, 282, 33788-33794.

185. Vorburger, T.; Ebneter, J.Z.; Wiedenmann, A.; Morger, D.; Weber, G.; Diederichs, K.; Dimroth, P.; von Ballmoos, C. Arginine-induced conformational change in the $c$-ring/ $a$-subunit interface of ATP Synthase. FEBS J. 2008, 275, 2137-2150.

186. Gaeta, F.S.; Bencivenga, U.; Canciglia, P.; Rossi, S.; Mita, D.G. Temperature gradients and prebiological evolution. Cell Biochem. Biophys. 1987, 10, 103-125.

187. Silverman, M.; Simon, M. Flagellar rotation and the mechanism of bacterial motility. Nature 1974, 249, 73-74.

188. Neidhart, F.C. Chemical composition of Escherichia coli. In Escherichia coli and Salmonella typhimurium: Cellular and Molecular Biology; Neidhart, F.C., Ingraham, J.L., Low, K.B., Magasanik, B., Schaechter, M., Umbarger, H.E., Eds.; American Society for Microbiology: Washington, DC, USA, 1987; pp. 3-6.

189. Chng, C.-P.; Kitao, A. Thermal unfolding simulations of bacterial flagellin: insight into its refolding before assembly. Biophys. J. 2008, 94, 3858-3871.

190. MacNab, R.M. How bacteria assemble flagella. Annu. Rev. Microbiol. 2003, 57, 77-100.

191. Imada, K.; Minamino, T.; Tahara, A.; Namba, K. Structural similarity between the flagellar type III ATPase FliI and F-ATPase subunits. Proc. Nat. Acad. Sci. USA 2007, 104, 485-490.

192. Larsen, S.H.; Adler, J.; Gargus, J.J.; Hogg, R.W. Chemomechanical coupling without ATP: the source of energy for motility and chemotaxis in bacteria. Proc. Nat. Acad. Sci. USA 1974, 71, 1239-1243.

193. MacNab, R.M. An entropy-driven engine-the bacterial flagellar motor. In Biological Structures and Coupled Flows; Oplatka, A., Balaban, M., Eds.; Academic Press: New York, NY, USA, 1979; pp. 147-160. 
194. Webre, D.J.; Wolanin, P.M.; Stock, J.B. Bacterial chemotaxis. Curr. Biol. 2003, 13, R47-R49.

195. Brown, P.N.; Terrazas, M.; Paul, K.; Blair, D.F. Mutational analysis of the flagellar protein FliG: sites of interaction with FliM and implications for organization of the switch complex. J. Bacteriol. 2007, 189, 305-312.

196. Cohen-Ben-Lulu, G.N.; Francis, N.R.; Shimoni, E.; Noy, D.; Davidov, Y.; Prasad, K.; Sagi, Y.; Cecchini, G.; Johnston, R.M.; Eisenbach, M. The bacterial flagellar switch complex is getting more complex. EMBO J. 2008, 27, 1134-1144.

197. Mashimo, T.; Hashimoto, M.; Yamaguchi, S.; Aizawa, S.-I. Temperature-hypersensitive sites of the flagellar switch component FliG in Salmonella enterica Serovar Typhimurium. J. Bacteriol. 2007, 189, 5153-5160.

198. Kojima, S.; Blair, D.F. Conformational change in the stator of the bacterial flagellar motor. Biochemistry 2001, 40, 13041-13050.

199. Schmitt, R. Helix rotation of the flagellar rotary motor. Biophys. J. 2003, 85, 843-849.

200. Metzner, P. Die Bewegung und Reizbeantwortung der bipolar begeißelten Spirillen. Jahrbücher f. Wissensch. Botanik 1920, 59, 325-412.

201. Paster, E.; Ryu, W.S. The thermal impulse response of Escherichia coli. Proc. Nat. Acad. Sci. USA 2008, 105, 5373-5377.

202. Liu, R.; Ochman, H. Stepwise formation of the bacterial flagellar system. Proc. Nat. Acad. Sci. USA 2007, 104, 7116-7121.

203. Hasegawa, E.; Kamiya, R.; Asakura, S. Thermal transitions in helical forms of Salmonella flagella. J. Mol. Biol. 1982, 160, 609-621.

204. Turner, L.; Caplan, S.R.; Berg, H.C. Temperature-induced switching of the bacterial flagellar motor. Biophys. J. 1996, 71, 2227-2233.

205. Wang, G.M.; Sevick, E.M.; Mittag, E.; Searles, D.J.; Evans, D.J. Experimental demonstrations of violations of the second law of thermodynamics for small systems and short time scales. Phys. Rev. Lett. 2002, 89, 0500601.

206. Ritort, F. Work fluctuations, transient fluctuations of the second law and free-energy recovery methods. Poincaré Seminar 2003, 2, 195-229.

207. Filliger, R.; Reimann, P. Brownian gyrator, a minimal heat engine on the nanoscale. Phys. Rev. Lett. 2007, 99, 230602.

208. Chapman, V.J. The Algae; MacMillan: London, UK, 1962.

209. Pringsheim, E.G. Farblose Algen. Ein Beitrag zur Evolutionsforschung; Gustav Fischer: Stuttgart, Germany, 1963.

210. Seilacher, A. Biomat-related life styles in the Precambrian. Palaios 1999, 14, 86-93.

211. Schulze-Makuch, D.; Irwin, L.N. Energy cycling and hypothetical organisms in Europa's ocean. Astrobiology 2002, 2, 105-121.

212. Beynon, R.P.; Bahl, V.K.; Prendergast, B.D. Infective endocarditis. Br. Med. J. 2006, 333, 334-339.

213. Jørgensen, C.B. Comparative physiology of suspension feeding. Annu. Rev. Physiol. 1975, 37, 57-79.

214. Ferguson, F.D. Systems and methods for tethered wind turbines. U.S.Patent 7335000, 2005. 
215. Reimann, P.; Hänggi, P. Introduction to the physics of Brownian motors. Appl. Phys. A 2002, 75, 169-178.

216. Bao, J.-D. Directed current of Brownian ratchet randomly circulating between two thermal sources. Physica A 1999, 273, 286-293.

217. Li, Y.-X. Transport generated by fluctuating temperature. Physica A 1997, 238, 245-251.

218. Reimann, P.; Bartussek, R.; Häußler, R.; Hänggi, P. Brownian motors driven by temperature oscillations. Phys. Lett. A 1996, 215, 26-31.

219. Zhang, Y.; Chen, J. Investigation on a temporal asymmetric oscillation temperature ratchet. Physica A 2008, 387, 3443-3448.

220. Bennett, C.H. The thermodynamics of computation-a review. Int. J. Theor. Phys. 1982, 21, 905-940.

221. Bennett, C.H. Logical reversibility of computation. IBM J. Res. Dev. 1973, 6, 525-532.

222. Benioff, P.A. Quantum mechanical models of Turing Machines that dissipate no energy. Phys. Rev. Lett. 1982, 48, 1581-1585.

223. Headrick, M.V. Clock and Watch Escapement Mechanics. Available online: http: //www.abbeyclock.com/escpdf.html 1997 (accessed September 16, 2009).

224. Huxley, A.F. Reflexions on Muscle; Princeton University Press: Princeton, MA, USA, 1981.

225. Lowry, D.S.; Frasch, W.D. Interactions between $\beta$ D372 and $\gamma$ subunit N-terminal residues $\gamma$ K9 and $\gamma \mathrm{S} 12$ are important to catalytic activity catalyzed by Escherichia coli $\mathrm{F}_{1} \mathrm{~F}_{\mathrm{o}}$-ATP Synthase. Biochemistry 2005, 44, 7275-7281.

226. Schilstra, M.J.; Martin, S.R. An elastically tethered viscous load imposes a regular gait on the motion of myosin-V. Simulation of the effect of transient force relaxation on a stochastic process. J. Royal Soc. Interface 2006, 3, 153-165.

227. Petzold, C. The Annotated Turing: a Guided Tour through Alan Turing's Historic Paper on Computability and the Turing Machine; Wiley: Indianapolis, IN, USA, 2008.

228. Chaitin, G.J. Thinking about Gödel and Turing; World Scientific: Singapore, 2007.

229. Kleene, S.C. Mathematical Logic; Wiley: New York, NY, USA, 1967.

230. Perlis, A.J. Epigrams on Programming. SIGPLAN Notices 1982, 17, 7-13.

231. Stepney, S. The neglected pillar of material computation. Physica D 2008, 237, 1157-1164.

232. Bennett, C.H. Dissipation-error tradeoff in proofreading. BioSystems 1979, 11, 85-91.

233. Von Neumann, J. Probabilistic logics and the synthesis of reliable organisms from unreliable computers. In Automata Studies; Shannon, C.E., McCarthy, J., Eds.; Princeton University Press: Princeton, MA, USA, 1956; pp. 43-98.

234. Danchin, A. The Delphic Boat: What Genomes Tell Us; Harvard University Press: Cambridge, MA, USA, 1998.

235. Berg, H.C. Touring machines. Curr. Biol. 1996, 6, 624.

236. Tomizaki, K.-Y.; Mihara, H. Phosphate-mediated molecular memory driven by two different protein kinases as information input elements. J. Am. Chem. Soc. 2007, 129, 8345-8352.

237. Teuscher, C.; Nemenman, I.; Alexander, F.J. Novel computing paradigms: Quo vadis? Physica D 2008, 237, v-viii.

238. Ben-Jacob, E. Bacterial wisdom. Physica A 1998, 249, 553-557. 
239. Ben Jacob, E. Seeking the foundations of cognition in bacteria: from Schrödinger's negative entropy to latent information. Physica A 2006, 359, 495-524.

240. Hellingwerf, K.J. Bacterial observations: a rudimentary form of intelligence. Trends Microbiol. 2005, 13, 152-158.

241. Casadesús, J.; D’Ari, R. Memory in bacteria and phage. BioEssays 2002, 24, 514-518.

242. Wolf, D.M.; Fontaine-Bodin, L.; Bischofs, I.; Price, G.; Keasling, J.; Arkin, A.P. Memory in microbes: quantifying history-dependent behaviour in a bacterium. PLOS ONE 2006, 3, 1-114.

243. Vellai, T.; Vida, G. The origin of eukaryotes: the difference between prokaryotic and eukaryotic cells. Proc. Roy. Soc. Lond. B 1999, 266, 1571-1577.

244. Margulis, L. Origin of Eukaryotic Cells; Yale University Press: New Haven, CT, USA, 1970.

245. Margulis, L. Symbiosis in Cell Evolution; Freeman: San Francisco, CA, USA, 1981.

246. Mitchell, D.R.; Nakatsugawa, M. Bend propagation drives central pair rotation in Chlamydomonas reinhardtii flagella. J. Cell Biol. 2004, 166, 709-715.

247. Omoto, C.K.; Kung, C. Rotation and twist of the central-pair microtubules in the cilia of Paramecium. J. Cell Biol. 1980, 87, 33-46.

248. Martin, W.; Müller, M. The hydrogen hypothesis for the first eukaryote. Nature 1998, 392, 37-44.

249. Andersson, S.G.; Karlberg, O.; Canback, B.; Kurland, C.G. On the origin of mitochondria: a genomics perspective. Phil. Trans. Roy. Soc. B 2003, 358, 165-177.

250. Cavalier-Smith, T. Origin of mitochondria by intracellular enslavement of a photosynthetic purple bacterium. Proc. Roy. Soc. B 2006, 273, 1943-1952.

251. Brennen, C.; Winet, H. Fluid mechanics of propulsion by cilia and flagella. Annu. Rev. Fluid Mech. 1977, 9, 339-398.

252. Adleman, L.M. Molecular computation of solution to combinatorial problems. Science 1994, 266, 1021-1024.

253. Benenson, Y.; Paz-Elizur, T.; Adar, R.; Keinan, E.; Livneh, Z.; Shapiro, E. Programmable and autonomous computing machine made of biomolecules. Nature 2001, 414, 430-434.

254. Faulhammer, D.; Cukras, A.R.; Lipton, R.J.; Landweber, L.F. Molecular computation: RNA solutions to chess problems. Proc. Nat. Acad. Sci. USA 2000, 97, 1385-1389.

255. Bray, D. Protein molecules as computational elements in living cells. Nature 1995, 376, 307312.

256. Unger, R.; Moult, J. Towards computing with proteins. Proteins 2006, 63, 53-64.

257. Kellogg, D.R.; Moritz, M.; Albertz, B.M. The centrosome and cellular organization. Annu. Rev. Biochem. 1994, 63, 639-674.

258. Aoyama, S.; Kamiya, R. Cyclical interactions between two outer doublet microtubules in split flagellar axonemes. Biophys. J. 2005, 89, 3261-3268.

259. Shingyoyi, C.; Higuchi, H.; Yoshimura, M.; Katayama, E.; Yanagida, T. Dynein arms are oscillatory force generators. Nature 1998, 393, 711-714.

260. Pan, J.; Snell, W. The primary cilium: keeper of the key to cell division. Cell 2007, 129, 1255-1257.

261. Pazour, G.J.; Witman, G.B. The vertebrate primary cilium is a sensory organelle. Curr. Opin. Cell Biol. 2003, 15, 105-110. 
262. Quarmby, L.M.; Parker, J.D.K. Cilia and the cell cycle? J. Cell Biol. 2005, 169, 707-710.

263. Mans, D.A.; Voest, E.E.; Giles, R.H. All along the watchtower: Is the cilium a tumor suppressor organelle? Biochim. Biophys. Acta 2008, 1786, 114-125.

264. Jekely, G.; Arendt, D. Evolution of intraflagellar transport from coated vesicles and autogenous origin of the eukaryotic cilium. BioEssays 2006, 28, 191-198.

265. Craddock, T.J.A.; Tuszynski, J.A. On the role of the microtubule in cognitive brain functions. NeuroQuantology 2007, 5, 32-57.

266. Hameroff, S.R.; Watt, R.C. Information processing in microtubules. J. Theor. Biol. 1982, 98, 549-561.

267. Hameroff, S. Quantum computation in brain microtubules? The Penrose-Hameroff 'Orch OR' model of consciousness. Phil. Trans. Roy. Soc. Lond. A 1998, 356, 1869-1896.

268. Tuszynski, J.A.; Hameroff, S.; Sataric, M.V.; Trpisova, B.; Nip, M.L.A. Ferroelectric behaviour in microtubule dipole lattices: implications for information processing, signalling and assembly/disassembly. J. Theor. Biol. 1995, 174, 371-380.

269. Agar, J.N. Thermogalvanic cells. Adv. Electrochem. Electroeng. 1963, 3, 31-121.

270. Han, T.M.; Runnegar, B. Megascopic algae from the 2.1 billion-year-old Negaunee Iron Formation, Michigan. Science 1992, 257, 232-235.

271. Simon, M.A. The Matter of Life. Philosophical Problems of Biology; Yale University Press: New Haven, CT, USA, 1971; pp. 151, 152, 161-162, 167.

272. Gould, S.J. Is a new and general theory of evolution emerging? Paleobiology 1980, 6, 116-130.

273. Gould, S.J. Tempo and mode in the macroevolutionary reconstruction of Darwinism. Proc. Nat. Acad. Sci. USA 1994, 91, 9413-9417.

274. Gould, S.J.; Eldredge, N. Punctuated equilibrium comes of age. Nature 1993, 366, 223-227.

275. Stanley, S.M. Macroevolution: Process and Product; Freeman: San Francisco, CA, USA, 1979.

276. Boyle, R.A.; Lenton, T.M. Fluctuation in the physical environment as a mechanism for reinforcing evolutionary transitions. J. Theor. Biol. 2006, 242, 832-843.

277. Kashtan, N.; Noor, E.; Alon, U. Varying environments can speed up evolution. Proc. Nat. Acad. Sci. USA 2007, 104, 13711-13716.

278. Martin, W. Archaebacteria (Archaea) and the origin of the eukaryotic nucleus. Curr. Opin. Microbiol. 2005, 8, 630-637.

279. Popper, C.R. Conjectures and Refutations: the Growth of Scientific Knowledge; Routledge: London, UK, 1963.

280. Cockell, C.S.; Westall, F. A postulate to assess 'habitability'. Int. J. Astrobiol. 2004, 3, 157-163. 


\section{Notes}

1 Thermosynthesis proposes a temporal order for the emergence of the arms of transfer RNA [5] that is consistent with the order obtained by phylogenetic structure analysis [97].

2 This protein with its long evolutionary history is still of importance: during cancer it is underexpressed [98].

3 Ancient organisms 'put on ice' in meteorites of terrestrial origin, either in orbit around the Sun or deposited in repositories on the Moon [144] (especial near the poles in crater interiors shaded from the Sun) or other celestial objects, could allow the testing of the models presented here. This refutes the objection against these models that they are in principle untestable.

4 Biological use of a thermal gradient across a biomembrane has previously been proposed [186], but is considered less plausible. The temperature difference across a biomembrane can only be small, given its thickness of a few $\mathrm{nm}$. As the difference between the thermal conductivities of a lipid membrane and water are expected to be small, a temperature gradient will not become concentrated in the membrane; in contrast, the high electrical conductivity of water does cause electric fields to be concentrated across the membrane.

5 Except for its much smaller size, the structure would resemble a wind turbine hanging under a balloon [214].

6 Non-dissipative or reversible computing is theoretically feasible [221], but no implementations have yet been proposed; a quantum computer [222] could also be reversible.

7 In a clock an escapement converts a rotary motion of the rotor (driven by a spring or weight) into a backand-forth motion [223].

8. Berg [235] has drawn attention to the similarity of tumbling in bacteria and human thinking: Is a similar strategy fundamental to the operation of our brains? Does the sort of irritability that enables $E$. coli to change directions enable us to change our minds? Is there a secret here, learned early in evolution, that helps us think?

9 The rotation of the central pair of microtubules observed in several eukaryotes [246,247] may be a relic of prokaryotic flagellar rotation.

10. A progenitor of goose-flesh?

11 In a transformed (tumour) cell the cellular computer could contain a changed program that results in a differently executed cell cycle: in that case cancer would be associated with a software bug. The difference between the normal and the transformed cell would then be very small, and hard to exploit by chemotherapy, as observed.

(C) 2009 by the authors; licensee Molecular Diversity Preservation International, Basel, Switzerland. This article is an open-access article distributed under the terms and conditions of the Creative Commons Attribution license (http://creativecommons.org/licenses/by/3.0/). 